Portland State University

PDXScholar

Summer 9-7-2017

\title{
Urban Impacts to Forest Productivity, Soil Quality, and Canopy Structure in Forest Park, Portland, Oregon
}

Andrew David Addessi

Portland State University

Follow this and additional works at: https://pdxscholar.library.pdx.edu/open_access_etds

Part of the Forest Sciences Commons, and the Plant Sciences Commons Let us know how access to this document benefits you.

Recommended Citation

Addessi, Andrew David, "Urban Impacts to Forest Productivity, Soil Quality, and Canopy Structure in Forest Park, Portland, Oregon" (2017). Dissertations and Theses. Paper 3881.

https://doi.org/10.15760/etd.5769

This Thesis is brought to you for free and open access. It has been accepted for inclusion in Dissertations and Theses by an authorized administrator of PDXScholar. Please contact us if we can make this document more accessible: pdxscholar@pdx.edu. 
Urban Impacts to Forest Productivity, Soil Quality, and Canopy Structure

in Forest Park, Portland, Oregon

by

Andrew David Addessi

A thesis submitted in partial fulfillment of the requirements for the degree of

\author{
Master of Science \\ in \\ Environmental Science and Management
}

Thesis Committee:

Marion Dresner, Chair

Martin Lafrenz

Robert Scheller

Portland State University

2017 


\begin{abstract}
Land use practices and exposure to low impact disturbances associated with an urban environment can alter forest structure and function. Past and ongoing research in Forest Park, a large urban forest in Portland, Oregon, suggests that mature mixed Douglas-fir (Psuedotsuga meziesii)-hardwood stands in the more urban end of the park lack a shade-tolerant conifer understory composed of the late successional conifer tree species, such western hemlock (Tsuga heterophylla) and western red-cedar (Thuja plicata). 5-year plot remeasurement data that characterizes productivity and mortality patterns did not show a strong relationship to urban proximity. Plot productivity was generally consistent with values taken from studies of other similarly aged ( $\sim 100$ years old) Douglas-fir /Western Hemlock stands. Mortality was highest in rural plots, and was driven by large windthrow events to canopy trees. Soil organic matter, soil $\mathrm{pH}$, and depth of organic horizon indicated a legacy of soil impact in urban areas most impacted by past intensive logging. The urban mature plot had higher mean soil $\mathrm{pH}$ at site $(5.87$, se: \pm 0.06$)$ compared to a rural mature, and old growth reference sites located within the park. Although surface organic and A layer soil horizon depth was thinnest at the urban mature site, soil organic matter was not found to be significantly different across sites. Light detection and ranging ( LiDAR) data showed that old-growth plots and plots in the middle section of the park had the highest degree of canopy structure as measured by Rumple and standard deviation of point elevation. Measures of stand height showed OG plots and urban plots to have the tallest trees. Rural plots showed a high degree of
\end{abstract}


variability in all LiDAR metrics, showing a wider range of stand height and complexity than urban and middle plots.

These results suggest that past land-use and urban proximity affect plot level productivity, soil quality, and above-ground canopy structure in Forest Park. These results clarify how the lack of late-successional tree species might be most linked to differing histories of intensive logging activity within the park. Reduced old-growth legacy features (remnant seed trees, coarse woody debris) in plots with a clear history of aggressive clear-cuts has led to a reduction in regeneration of western hemlock and western red-cedar in the understory. 


\section{Acknowledgements}

Thank you to the many students who have helped collect data used in this report, including: Noah Swerdloff, Jacob Argueta, Mia Jauregui, Sarah Copp, Hannah McDonald, Jill van Winkle and many others.

Thank you to my thesis committee, Marion Dresner, Martin LaFrenz, and Robert Scheller, as well as other professors, Yangdong Pan, Andres Holz, and Geoffery Duh, for guidance on this project.

Thank you to my wife, Terra and to the rest of our family for their love and support as I pursued this graduate work. 


\section{Table of Contents}

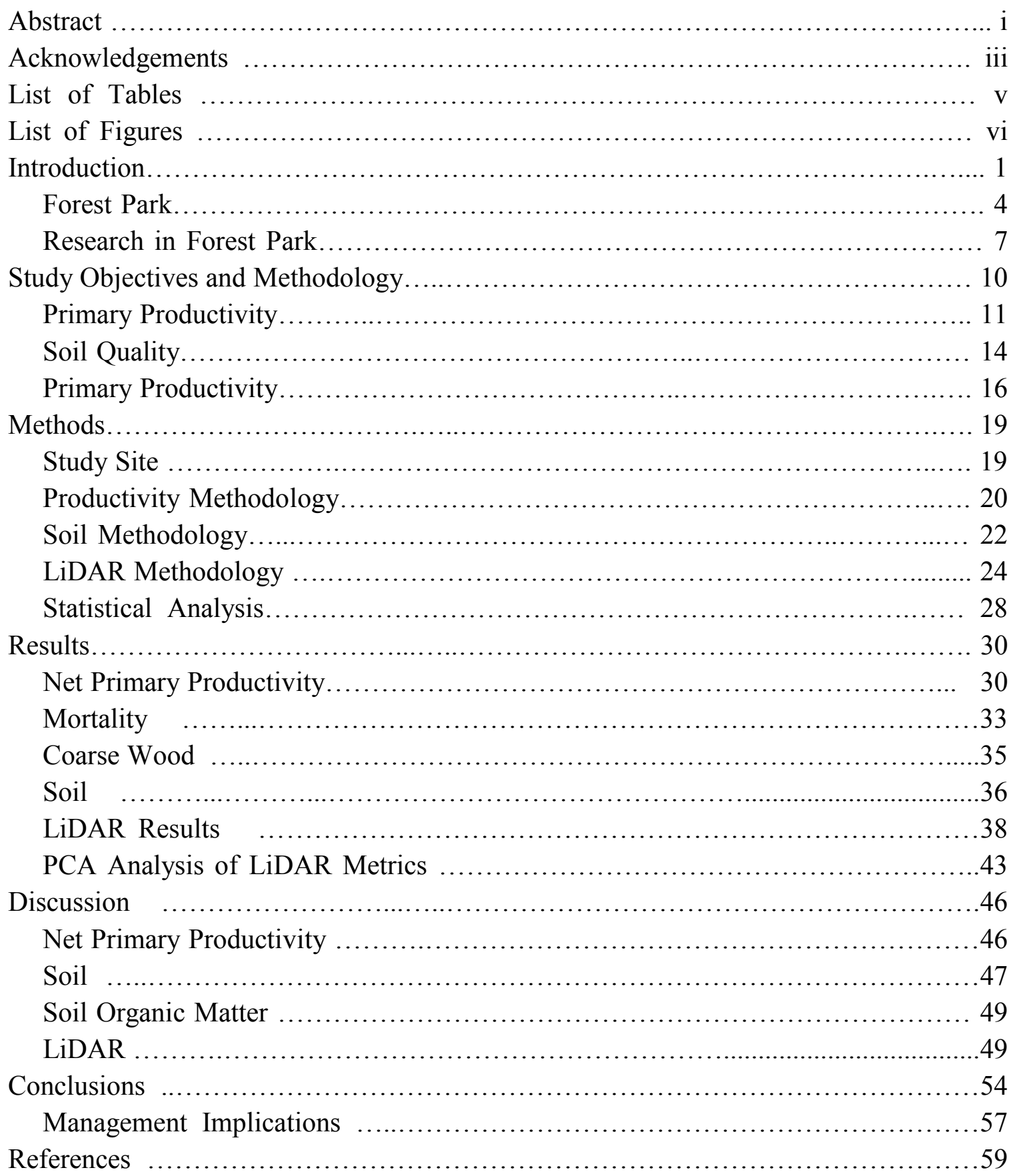




\section{List of Tables}

Table 1: Characteristics of sites analyzed in this study. ......................... 13

Table 2: Biomass change in each plot......................................... 31

Table 3: Biomass change for Canopy Douglas-fir in each plot $>90 \mathrm{~cm} \mathrm{DBH} \ldots \ldots \ldots . . . .32$

Table 4: Summary of LiDAR metrics for randomly sampled 1-hectare plots and LTER plots in Forest Park ..................................................... 40

Table 5: Loading of each variable within each component $\ldots \ldots \ldots \ldots \ldots \ldots \ldots \ldots \ldots \ldots . \ldots \ldots$

Table 6: The abundance of shade-tolerant conifer species in 4 plots in forest ........... 52 


\section{List of Figures}

Figure 1: Drivers of forest structure and function in Urban Forests.. .................. 2

Figure 2: Location of Forest Park relative to Portland, Oregon. ..........................

Figure 3: Map of tree locations in 4 long-term research plots used in this study .......... 9

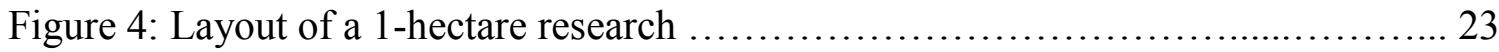

Figure 5: Location of 41 GIS generated random sample plots within Forest Park, as well

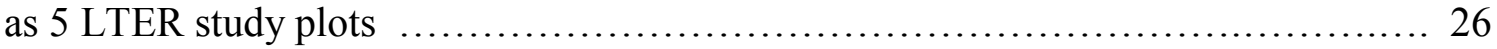

Figure 6: Example 3D LIDAR rendering using Fusion visualization software showing Burlington Plot (Rural old-growth).................................................. 28

Figure 7: Net Primary Productivity of Tree Boles (NPPB) for each plot at plot

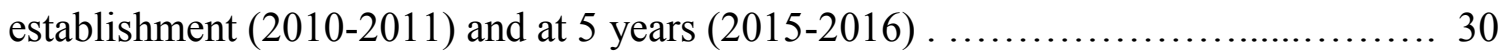

Figure 8: Biomass change of Large $(>90 \mathrm{~cm})$ Douglas-fir Trees ....................... 33

Figure 9: Causes of Mortality in each plot. ...................................... 34

Figure 10: Mortality by species........................................................ 35

Figure 11 Change in Coarse Woody Debris stock over 5 years, by plot.................. 36

Figure 12: Boxplots of soil $\mathrm{pH}$ values from four sites in Forest Park ................ 37

Figure 13: Boxplots of the percentage of organic matter in soil at four sites in Forest

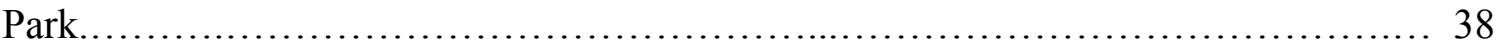

Figure 14: Boxplots of O/A depth measured in four sites in Forest Park. Because depth measurements showed a significant spatial autocorrelation, ANOVA tests were not run

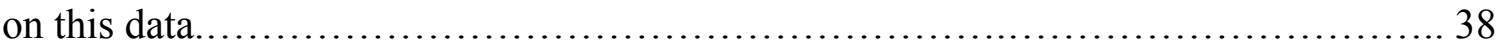

Figure 15: Boxplot 95th Percentile height of all 46 sample areas used in the LiDAR analysis. .......................................................................... 41

Figure 16: Boxplot of canopy rumple for all 46 sample areas used in the LiDAR

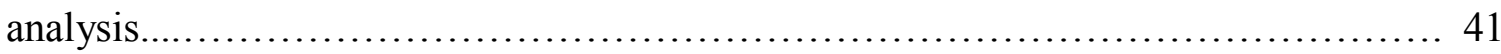

Figure 17: 3D LIDAR rendering of Audubon Plot (urban old-growth) and Coyote (Urban mature) using Fusion visualization software .......................................... 42 
Figure 18: Pearson correlation rank of all 8 LiDAR metrics used in this analysis

Figure 19: Bi-Plot of Principle Component Analysis Ordination of 8 LiDAR metrics for all 46 sampled plots ..................................................... 45 


\section{Introduction}

Urban forests, particularly large contiguous tracts of native vegetation, are important sources of ecosystem services in metropolitan areas. Urban forests support biodiversity (Alvey, 2006), air purification, and sequestration of greenhouse gases, as well as provide important cultural, educational, and recreational benefits for urban dwellers (Loeb, 2011). However, urban forest ecosystems face unique challenges as they are affected by a wide range of human, climatic, and natural disturbances (Figure 1). Urban impacts to forest ecosystem processes include altered climate due to the urban heat island effect, air pollution, trampling from recreational usage, and introduction of exotic species (Foster et al., 1997; McKinney, 2002; Foster et al., 2003 Carreiro and Tripler, 2005; Groffman et al., 2006; Zipperer and Guntenspergen, 2009). Furthermore, nearly all urban forests have been heavily affected by past land-use changes associated with the development of the surrounding city. These land-use changes include past logging for timber, conversion to agricultural and/or fire (Loeb, 2011). Thus, in urbanizing regions, factors driving forest development include both past and ongoing patterns of human activities. These factors can affect natural disturbance patterns and alter biogeochemical cycles (Figure 1; Grimm et al., 2000). Collectively, these impacts provide novel sets of conditions that affect the resilience and long-term sustainability of forest ecosystems (Medley et al., 1995). 


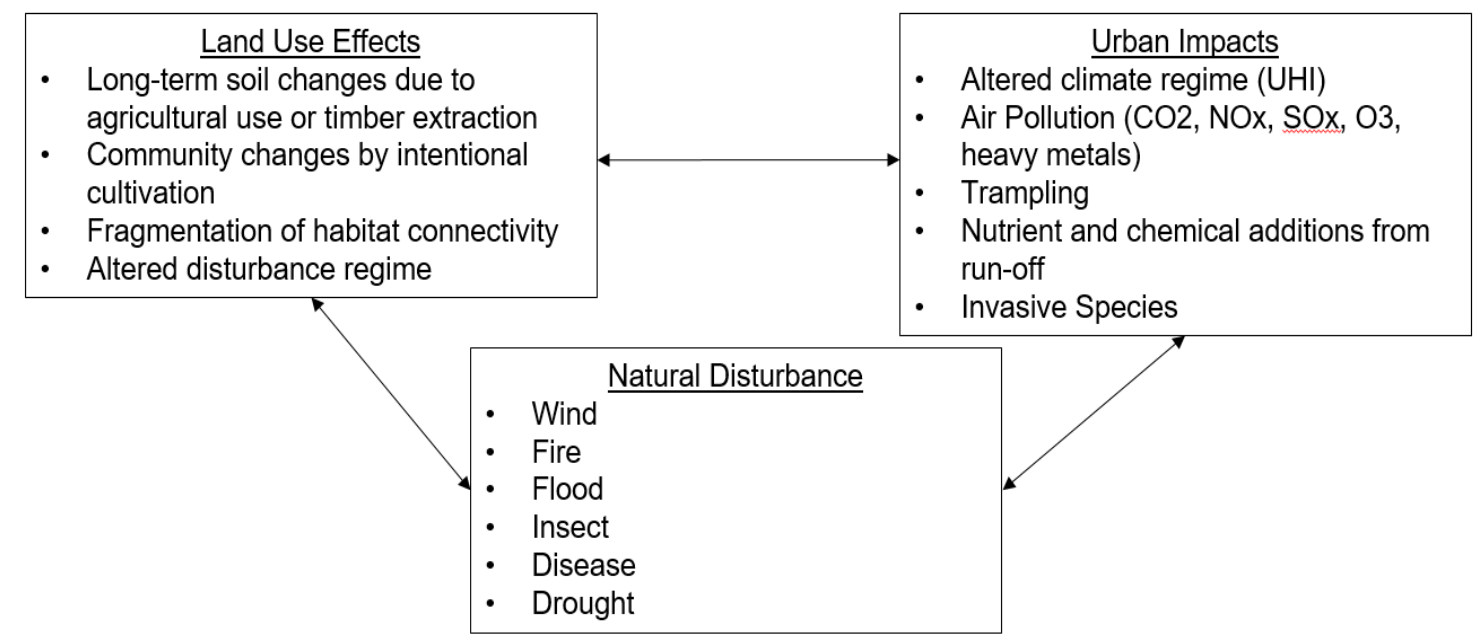

Figure 1: Drivers of forest structure and function in Urban Forests. Historic forests were mainly driven by the interaction of abiotic factor (such as climate, topography, and soil) with natural disturbance patterns. Managed forests are influenced by these same factors but with the addition of legacy effects of past land-use. In urban forests, additional anthropogenic impacts interact with land use effects and natural disturbance to create a complex and novel set of conditions that may alter forest development from historical conditions.

Forest ecosystems are typically resilient to natural disturbances, like wildfire, wind, landslides, insect outbreaks and disease. In many cases, these disturbances are an integral part of forest development, creating spatial and structural heterogeneity in forests. The Douglas-fir (Psuedotsuga menziesii)-western hemlock (Tsuga heterophylla) forests characteristic of Western Oregon are some of the most productive temperate forests in the world. Foresters and ecologists have studied these forests extensively, and the process by which they naturally develop over time has been well characterized.

Franklin et al., (2002) provides the most widely cited model of natural forest succession in Douglas-fir (Psuedotsuga menziesii)-western hemlock (Tsuga heterophylla) forests, but emphasize that their model is generalizable to nearly any temperate forest 
ecosystem that experiences stochastic and variable intensity natural disturbance. Their 8stage process highlights the role of natural disturbance in resetting a forest stand, and then driving its structural development toward old-growth over time. Stand initiation typically follows large or catastrophic disturbance such as fire, windthrow, landslide, flood, or disease/insect outbreak. In the first few decades, the Cohort establishment stage takes place as a new cohort of trees establishes from the natural seed bank or from the seed of remaining mature trees. When the stand is approximately $80-100$ years old, it generally transitions into the maturation stage signified by the pioneer canopy trees reaching maximum height and crown diameter. Other properties of this maturation stage include re-establishment of shade tolerant tree species such as western hemlock, western red-cedar, pacific yew and grand fir in the understory. Over the decades or centuries that follow, Vertical diversification occurs as shade tolerant conifers begin to grow vertically, exploiting increased light penetrating through the canopy due to gaps created by patchlike mortality to dominant Douglas-fir trees. Horizontal diversification occurs concurrently, as gap sizes increase and stands of shade tolerant conifers begin to become co-dominant with the initial Douglas-fir cohort. Overall, forest succession in the coastal Pacific Northwest can take several centuries to unfold, stretching from stand replacement to the development of old-growth features (Franklin et al., 2002).

Intensive logging practices characteristic of managed and historically harvested forests (which includes nearly all forests in urbanized regions) differs from natural disturbance in several ways that can have long-term consequences on the development of a forest stand. Whereas natural disturbances promote legacy features, such as coarse 
woody debris and dead standing snags, removal of wood for timber and the standard accompanying practice of burning logging slash can deplete nearly all legacy features from the resetting forest (Spies et al., 1988). These legacy features serve many important structural and ecological functions in a forest stand. They provide habitat for organisms, regulate energy flow and nutrient cycling, and influence soil and sediment transport and storage (Harmon et al., 1986; Hagan and Grove, 1999.)

Long-term research on urban forests, particularly approaches that use a paired or gradient approach to compare ecologically similar forests that differ in proximity to urban centers, can provide vital information on how terrestrial ecosystems are shaped by the interaction of these natural and anthropogenic disturbances (Foster et al., 2003; Carreiro and Tripler, 2005). While natural and anthropogenic impacts on forest ecosystems are recognized to affect both managed and unmanaged forests, urban forests are particularly susceptible to these stresses (Figure 1). Few ecosystems remain that are not to some degree influenced by anthropogenic changes like land use, climate change, air pollution, and introduction of exotic species. Thus, the study of urban forests can serve as a 'canary in the coal mine' - or rather, an early warning - for determining how global anthropogenic impacts may be affecting forests worldwide (O'Brien et al., 2012).

\section{Forest Park}

Forest Park is a unique urban forest. Forest Park stretches 11 kilometers in length along a northwest axis from the edge of Portland's urban core along the east slopes of the Tualatin Mountain Range, which run parallel to the Willamette River toward its 
confluence with the Columbia River (Figure 2). Forest park encompasses over 5,000 acres $(2,000$ hectares) and is managed by Portland Parks \& Recreation. It is considered the largest forested park within an urban boundary in the contiguous United States.

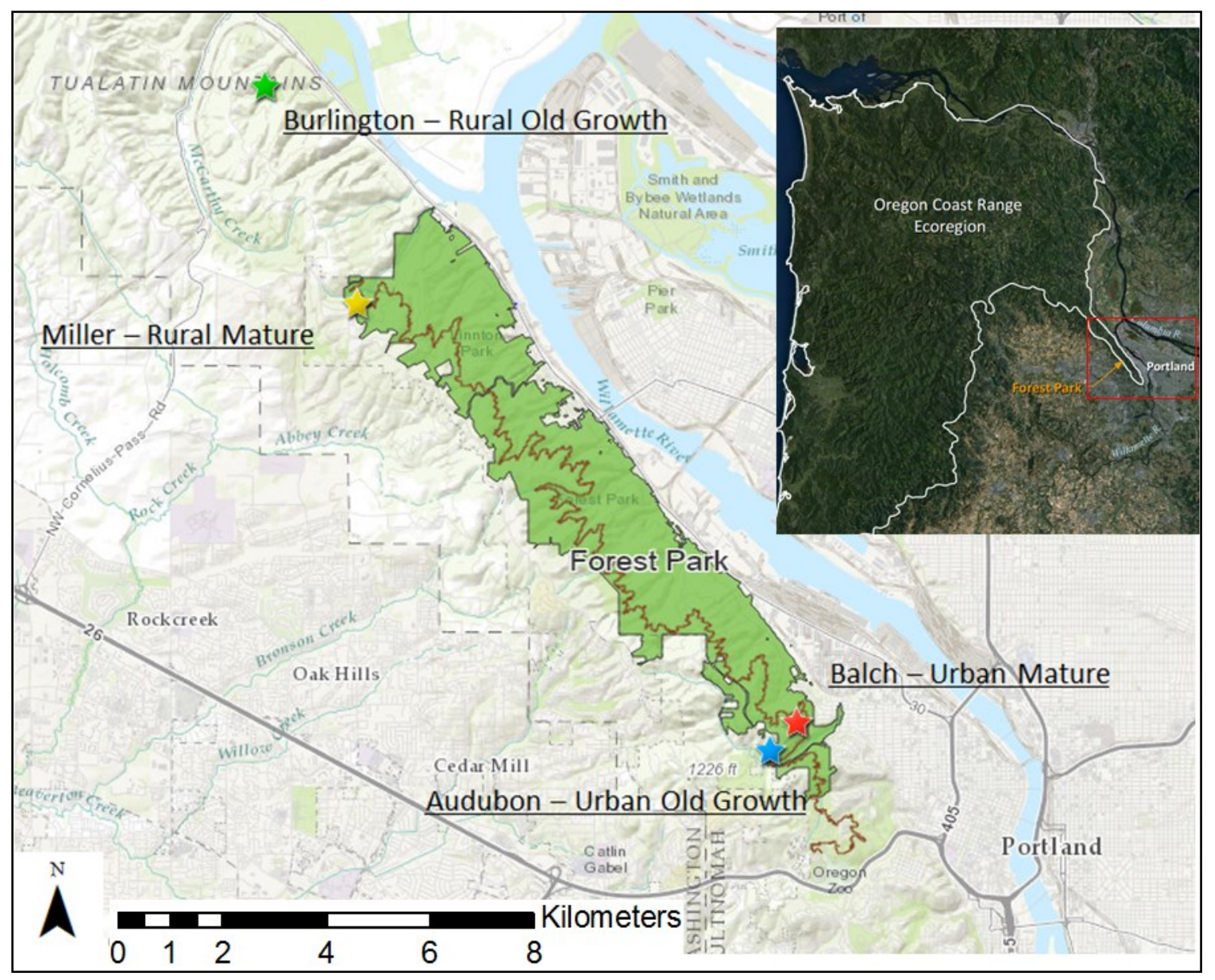

Figure 2: Location of Forest Park relative to Portland, Oregon. Locations of four of the six 1-hectare sites established for long-term research in Forest Park are indicated by stars. Excluded plots were not analyzed consistently in this report. The green shading indicates the boundary of Forest Park, and the brown line represents the Wildwood trail, a 30-mile hiking trail that traverses the entire extent of Forest Park. Forest Park is being managed to provide ecological connectivity from the Oregon Coast Range Ecoregion to the urban core and Willamette River Valley (inset, Forest Park Conservancy and Forest Park Alliance, 2013). 
Anthropogenic disturbances played an important role in shaping the vegetation of Forest Park in the centuries preceding its establishment as a nature park. Prior to European discovery, the banks of the Lower Columbia and Lower Willamette Rivers at the base of the Tualatin Mountains supported some of the densest settlements of indigenous peoples in the America's. However, the forested hillsides were not regularly settled but rather used for hunting, foraging, or travel to the Tualatin valley west of the ridge (Rubin, 1999). Early descriptions of the hillsides by the Lewis and Clark expedition noted documented abundant stands of large and varied conifer trees characteristic of old growth Douglas-fir/Western hemlock forests of the region. These include Douglas-fir, Western hemlock, Western red cedar and Grand fir (Abies Grandis). Patches of young forests that include deciduous tree species like Big-leaf maple (Acer macrophyllum) and Red alder (Alnus rubra) were also described (DeVoto, 1953; Munger, 1960).

Major European settlements near present day Forest Park developed in the 1840's, and major land use changes occurred throughout the area encompassing the park soon after. However, given the large area involved, the timing and intensity of land-use changes differed between sections of the present day park. Level land atop the ridge and west of the Tualatin Mountains were developed for farmsteads, while the steep hillsides were utilized for timber (Munger, 1960). The hills adjacent to the new settlements of Portland and Linnton along the river were logged repeatedly by early settlers in the mid19th through the first half of the 20th centuries. Primitive logging "skid-roads" still course through portions of the park to this day. Fire-wood salvaging was also frequent adjacent to the neighborhoods of present day Portland. Some portions of the park were 
donated for park preserves as early as 1897 (i.e. Macleay Park), sparing some sections of the park from a wave of logging in the 1920's and 1930's (Munger, 1960). In addition to repeated clear-cut logging, large swaths of the park have experienced stand-replacing wildfires on at least 3 occasions, in 1889, 1940, and 1951, with the central portions of the park most affected by the latter of these fires. (Munger 1960; Kuhn, 2005; Houle, 2010).

Forest Park was formally dedicated as a city nature park in 1948 following several decades of public land acquisition. Today, Forest Park is an important recreational asset for the city, but it is also being managed to accomplish several ecological objectives. These objectives include ecological connectivity from the Oregon Coast Range to the Portland Metro area, and for the natural development of a diversity of habitats including old growth forests with characteristics such as open spaces, downed wood, off-channel aquatic habitat, and inputs of large wood to streams (Forest Park Conservancy and Forest Park Alliance, 2013). However, threats common to many urban forests, such as habitat fragmentation, non-native species, climate change, and the legacy of historical land uses, are cited as challenges to reaching these desired ecological conditions (Forest Park Conservancy and Forest Park Alliance, 2013).

\section{Research in Forest Park}

Recent ecological research in Forest Park has revealed that 80-100 year old mixed-conifer stands, which are transitioning through what Franklin et al. (1981) would call a maturation stage, are dominated by relatively even aged cohort of Douglas-fir, and Big-leaf maple (Acer macrophyllum). However, there is a relative lack of shade-tolerant 
conifers or their saplings in urban stands (Figure 3; Broshot, 2007; Dresner et al., in review). Broshot (2011) also found the urban forest stands to be experiencing greater tree mortality and less sapling recruitment overall (Broshot, 2011). This is in contrast to the rural reach of the park to the north where similarly aged stands have a greater diversity of late successional shade-tolerant conifer species. Broshot $(2007 ; 2011)$ concluded that there is an urban-to-rural gradient of anthropogenic effects on the forest that is driving these diverging successional trajectories. However, it is unclear which specific ecological factors are most influencing these differences in stand development.

In the past decade, researchers from the Dresner Lab at Portland State University have established six 1-hectare long-term research plots throughout Forest Park distributed using a paired approach. Three stands were established in the urban end of the park and three are in the rural extent (4 of these 6 plots are shown in Figure 3). Site locations were carefully selected to be accessible by the trail network within the park, but set back from established trails so that the general public would not tamper with them. All sites were selected to be characterized by mixed conifer-hardwood stands, which were distinguished in age as "mature" or "old-growth." In this research, mature is used to distinguish stands aged approximately 100 years old from sites containing a few trees in excess of 100 years old. The "old-growth" stands do not technically meet all of the old-growth classification (Franklin and Spies, 1991) since the proportion of old trees is too small (Broshot, 2011). However, they are among the oldest stands within Forest Park and serve as "old-growth" reference sites for studies in our long-term research plots. 


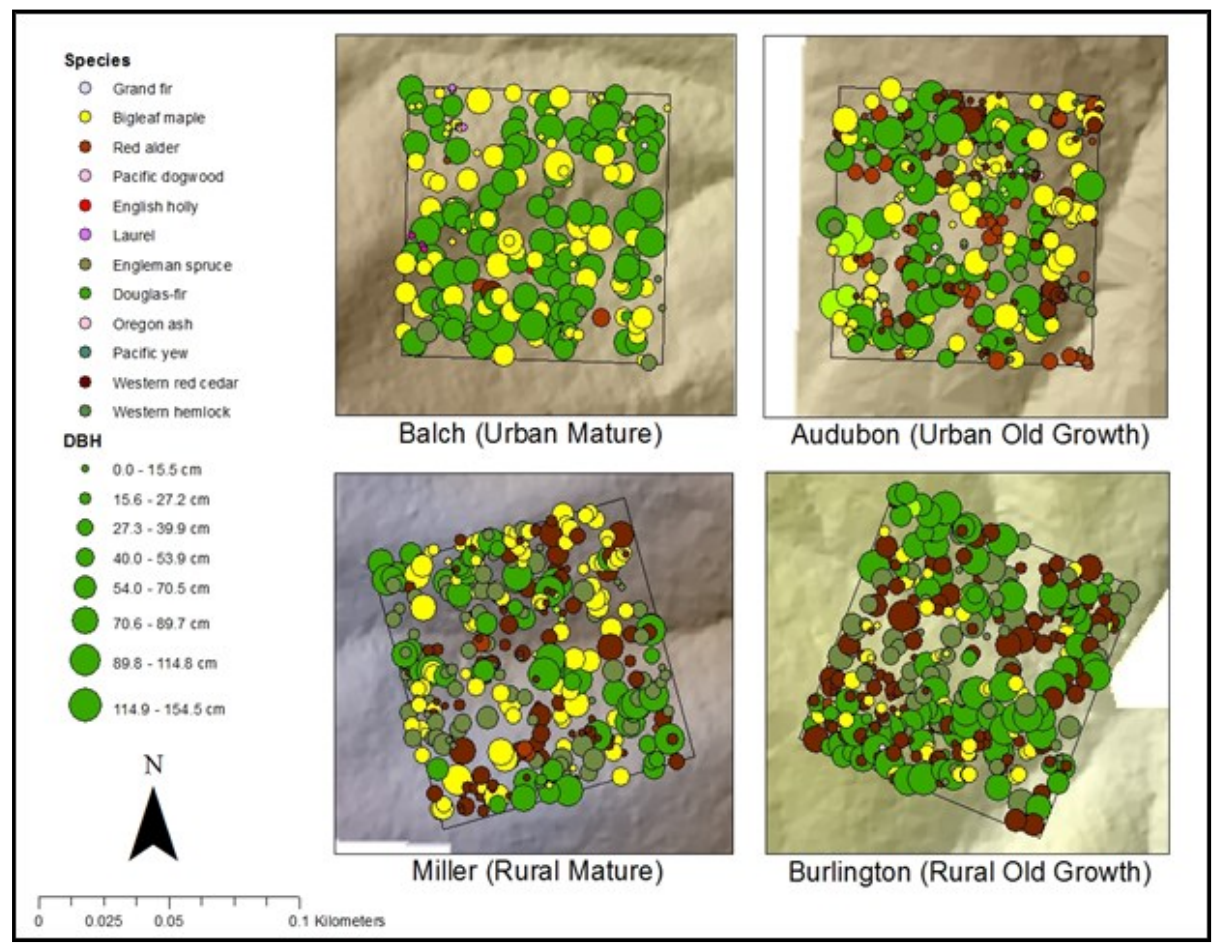

Figure 3: Map of tree locations in 4 long-term research plots used in this study. This map shows species and size distribution of each tree in 2012-2017, as well as a shaded hill map showing topography. Note reduced density of brown and dark green circles in the upper left panel, representing the lack of late successional conifers- western hemlock and western red cedar-in Balch (the urban mature plot). Also, note the relative lack of small circles in Balch, reflecting a lack of young trees in the urban plot.

Past research in Forest Park by the Dresner Lab has documented the effects of some of the impacts relevant to urban forests. Van Winkle (2014) showed that increased human traffic along informal trails can cause localized soil compaction and serve as a vector for spread of invasive and ruderal plant species. Copp (2014) looked at understory plant species within two urban research plots and documented a growing invasion of English ivy/Irish ivy (Hedera spp.) in urban plots. She found ivy coverage was correlated with a decrease in the richness, diversity, and cover of native ground cover species. Collectively, this work gives evidence that vegetation in the urban end of the park is more 
vulnerable to human traffic and the spread of invasive species than the rural portion of the park.

\section{Study Objectives and Methodology}

This thesis builds on previous research performed by the Dresner Lab in the longterm study plots in Forest Park. This research was performed over the course of 20152017, while helping to maintain these plots and recollect the first set of 5 year measurements. There were several overarching research questions that guided this research:

- To what degree are maturing mixed conifer stands in Forest Park developing structural and compositional features representative of old growth Douglas-fir - Western hemlock forest?

- Why are we seeing lack of shade-tolerant conifer regeneration in the urban end of Forest Park compared to the rural end of the park?

- To what degree are these patterns reflective of urbanization, legacies of past land-use, or within the range of natural variability?

- How can long-term research in these study plots inform management on how to achieve desired ecological conditions throughout Forest Park

To help shed light on these questions, I pursued three main lines of investigation related to stand productivity, soil health, and canopy structure. Collectively, this information helps characterize these forest plots and could inform future research and 
management objectives in Forest Park, as well as in other large urban and managed forests.

\section{Primary Productivity:}

The productivity of a forest is the rate at which plants accumulate biomass. Living tree boles make up a substantial portion of the total biomass of the forest. Studies estimate that living trees make up $40-70 \%$ of the total non-mineral soil carbon in a forest. Snags, coarse woody debris (CWD), shrubs, and litter make up the most of the rest (Acker et al., 2002; Gray et al., 2016). Mortality and subsequent breakdown of plant biomass is also a critical step in forest successional development. Thus, understanding the balance of productivity and mortality is critical to understanding forest dynamics and nutrient cycles (Dixon et al., 1994; Acker et al., 2002, McKinley et al., 2011, Gray et al., 2016).

Productivity of mixed conifer forests depends on a number of factors, including nutrient availability and abiotic conditions such as climate, topography and geology/soil (Gray et al., 2016). There is also a strong asymptotic trend of productivity with stand age such that the rate of biomass accumulation generally peaks around the stage of stand closure, and then the rate gradually declines as forests mature. In old-growth stands the net increase in biomass approaches zero as mortality to large canopy trees and subsequent breakdown of downed wood (also called heterotrophic respiration) counterbalances the biomass accumulation of remaining live vegetation (Janisch and Harmon, 2002, Gray et al., 2016). Most studies of the relationship of forest productivity to stand age utilize a 
chronosequence approach, observing stands along an age gradient to determine productivity rates. However, there are relatively few studies that have investigated productivity patterns based on repeated long-term measurements of plots due to the challenges of maintaining longitudinal research over very long time scales (Acker et al., 2002).

Urban proximity affects tree growth and mortality in complex ways. Increased $\mathrm{CO} 2$ concentrations from nearby anthropogenic emissions and temperature may enhance tree growth (O'Brien et al., 2012), but ozone and other air pollutants may decrease tree growth and lead to mortality (Gregg et al., 2003). Broshot (2011) found a high rate of mortality, and a low amount of sapling recruitment across Forest Park. It is not clear if this is a trend due to urban impacts specifically, or perhaps due to general climate change patterns like more common periods of extreme heat and drought that are causing tree mortality across the Western United States (Van Mantgam et al., 2009). In Forest Park, we have the opportunity to monitor how productivity and mortality of a large contiguous urban forests is influenced by the combination of urban, land-use and natural factors.

For 4 of the 6 plots long term research plots, I collected and analyzed tree diameter at breast height $(\mathrm{DBH})$ measurements and compared these values to initial plot data taken in 2010-2012. I determined rates of forest biomass accumulation and I also recorded instances of mortality. I also noted presumed cause of mortality and whether the dead bole contributed to CWD on the ground, or remained standing as a snag feature. In addition, I sub-sampled the tallest canopy Douglas-fir trees in each plot and estimated 
rate of biomass accumulation for these trees to assess how individual rates of tree growth might be affected by plot location.

We assumed that forest productivity and mortality patterns would be similar across plots and consistent with published values for similarly aged Douglas-fir dominant forests of Coastal Oregon. However, we considered that strong deviations from expected patterns could help reveal if stand productivity and mortality are being influenced by urbanization or past land use.

Hypothesis: Productivity and mortality patterns for these plots would be similar among mature plots as canopy trees are relatively close in age (reflecting similar timing of last major stand altering disturbance) and plot elevation, aspect, slope, and watershed position are similar (Table 1; McDonald 2011; Dresner et al., in review).

Table 1: Characteristics of sites analyzed in this study. DBH: Diameter of tree at Breast-Height.

\begin{tabular}{|c|c|c|c|c|}
\hline Site Name & Balch & Audubon & Miller & Burlington \\
\hline Site Category & $\begin{array}{l}\text { Urban } \\
\text { Mature }\end{array}$ & $\begin{array}{l}\text { Urban } \\
\text { Old-Growth }\end{array}$ & $\begin{array}{l}\text { Rural } \\
\text { Mature }\end{array}$ & $\begin{array}{l}\text { Rural } \\
\text { Old-Growth }\end{array}$ \\
\hline Distance to Portland City Courthouse (km) & 3.8 & 4.2 & 14.6 & 18.5 \\
\hline Elevation $(\mathrm{m})$ & $142-195$ & $152-186$ & $213-268$ & $70-114$ \\
\hline Average Slope (degrees) & 8 & 5.8 & 7.2 & 8.4 \\
\hline Stand age (90th percentile) & 100 & 110 & 100 & 150 \\
\hline Mean DBH $(\mathrm{cm})$ & 46.2 & 33.8 & 37.5 & 42.2 \\
\hline $\mathrm{SD} D B H(\mathrm{~cm})$ & 28.2 & 29.3 & 24.4 & 30.2 \\
\hline Tree Density (per hectare) & 254 & 413 & 368 & 395 \\
\hline Tree Density > $100 \mathrm{~cm}$ DBH (per hectare) & 4 & 21 & 7 & 27 \\
\hline Density Shade Tolerant Conifers (per hectare) & 25 & 179 & 200 & 236 \\
\hline
\end{tabular}




\section{Soil Quality}

Land use practices are recognized to have lasting effects on the physical, chemical, and biological properties of soil, sometimes for millennia (Dupouey et al., 2002). However, a large body of forestry research offers contradictory conclusions regarding the degree logging practices affect forest soils over time. Some of this variation is due to different sampling methods and variation in soil responses based on soil type (Nave et al., 2010, James and Harrison, 2016). Forest harvest can deplete the organic mass of the forest floor for at least several decades, the response following a characteristic U-shaped curve (Covington, 1981). Decomposing matter is high following a clear-cut, but less when a prescribed fire is used. As a young cohort reaches 20-40 years old and canopy closure begins, there is a drop in forest floor organic matter as the logging slash is fully broken down. It is generally assumed that a large input of CWD comes through the stem exclusion stage as overly dense and even aged trees crowd each other out and suppress less competitive trees. However, studies of long-term soil changes in plots that were harvested more than 60 years prior are generally lacking in the literature.

Soil organic matter (OM) is an important general indicator of soil health and has been widely used to determine the effects of forest management on long-term productivity of forest ecosystems (Schoenholtz et al., 2000, Seely et al., 2010). Soil OM is the result of decomposing plant and animal material and is vital to holding nutrients 
available for plant roots. It is also a key component of soil structure and contributes to the water holding capacity of the soil. A relative lack of soil OM would indicate diminished ability for the soil to support a productive stand. Surface erosion or mass flow triggered by land practices that alter the forest floor, such as logging and fire, can deplete the upper horizons of the soil that are rich in organic matter (Grigal, 2000). This effect could be compounded by a lack of CWD, which would serve to replenish the soil OM over time.

Soil $\mathrm{pH}$ is also an important general indicator of forest soil health as changes in pH can alter a host of nutrient cycling cascades (Schoenholtz et al., 2000). Changes to soil $\mathrm{pH}$ can shift the concentration of available forms of limiting nutrients (such as nitrogen) in ways that have differential effects on late-successional tree species (Kronzucker et al., 1997). Stand clearing disturbances, such as fire or logging, have been shown to raise the $\mathrm{pH}$ of forest soil (Pennock and Van Kessel, 1997), although it is not clear how long these changes persist following logging. Forest soils of the Pacific Northwest, the region of our study, are generally highly acidic, and shade tolerant conifers native to the region are particularly well adapted to low pH soils (Krajina et al., 1973). Alterations in soil $\mathrm{pH}$ may make shade tolerant conifers less competitive with early successional tree species or herbaceous plants by altering the predominant form of nitrogen or the availability of other nutrients in ways that favor early successional species.

I sought to determine whether there were differences in important soil quality indicators between sites. I sampled the organic matter content and $\mathrm{pH}$ of the top 10 centimeters of mineral soil cores from four of the six LTER sites in Forest Park. I also 
measured the depth of surface mineral soil horizons between sites. I expected soil health, as indicated by mineral soil $\mathrm{OM}$ and $\mathrm{pH}$ would show differences at the plot level in response to the degree of obvious and historical evidence of intensive logging in the plot. This would more broadly support evidence that soil degradation is related to intensity of past land use, and may be a link to the altered successional trends between sites (Figure 3; Broshot, 2007; McDonald, 2011; Dresner et al., in review).

Hypothesis: Balch, the urban mature site that lacks CWD, retains remnant skid trails, and shows clear signs of mass soil erosion, will show lower mineral soil $\mathrm{OM}$ and higher $\mathrm{pH}$ than the other stands that have less obvious signs of intensive land-use practices.

\section{LiDAR Analysis of Canopy Structure}

Forest canopy structure- the three dimensional arrangement of trees and their canopy crowns- is an important attribute of developing forests (Kane et al., 2000b). Canopy structural diversity is largely dependent on stand age, which is determined by the most recent stand clearing disturbance, whether natural or human induced. However, the interaction of past land management and urban impacts may limit the development of canopy structure by favoring even-aged stands with less species diversity. Young forests, particularly plantation forests with a monocrop of Psuedotsuga, exhibit very low canopy structure. However, as stands mature they can transition through a range of structural states while developing the canopy complexity that is characteristic of old-growth forests (Kane et al., 2000b). A range of ecosystem niches emerge among the many layers of the 
structurally complex canopy, and from the standing snags and large fallen CWD formed in the process of maturation (Van Pelt and Nadkarni, 2003). Structural features can contribute to important biodiversity and ecosystem functions (Ishii et al., 2004).

The application of light detection and ranging ( LiDAR) imaging analysis to study forests is a quickly developing field of research (see Gatziolis \& Andersen, 2008; Wulder et al., 2008, 2012). Airborne Laser Scanning can be used as a tool to gather remote data about forest stand characteristics over large areas (Lefsky et al., 2002; Gatziolis \& Andersen, 2008; Wulder et al., 2012). Many research designs have compared field based inventory data with metrics derived from LiDAR data to validate LiDAR as a complementary or stand-alone survey tool for forests. Because tree height shows a strong relationship to other commonly acquired structural properties like tree biomass, leaf-area index, and stand age, LiDAR can be paired with regionally developed allometric equations to estimate tree and plot level properties. Studies have successfully applied LiDAR analysis to determine forest stand features such as stand biomass/volume, canopy structure, and productivity in forested biomes across the world (e.g., Patenaude et al. 2004; Naesset \& Gobbaken, 2005; Yu et al., 2006; Zolkos et al., 2013).

My goals for this analysis were to explore how LiDAR data might complement plot-level observations from the long-term research plots and extend this understanding to other sections of Forest Park. LiDAR datasets of the Portland metropolitan area had been previously acquired by Metro regional government, and were available to university researchers. I used ArcGIS (Version 10.4, ESRI) together with Fusion LiDAR analysis software (USDA) to extract and analyze LiDAR point cloud files for 5 of our 6 LTER 
plots as well as 41 randomly sampled 1-hectare sites located in mixed conifer forest stands throughout Forest Park. This was done to determine variability in mature mixed conifer forest structure covering the full extent of the park, and to determine if canopy structure varied along an urban-rural gradient. I also sought to determine if our long-term research plots' canopy characteristics are similar to other mixed conifer-hardwood stands in their respective regions of the park, which would give support for the use of these long-term research plots to generalize about forest structure dynamics across wider areas of Forest Park.

Hypothesis: LiDAR metrics would indicate an urban-rural gradient of canopy structure consistent with successional patterns; urban plots having the least canopy structure, rural plots having intermediate canopy structure, and Old growth plots with the most developed canopy structure.

Mixed conifer-hardwood stands in the middle section of the park will be more similar to rural plots than urban plots, due to their relative distance from the urban center and more variable disturbance history. 


\section{Methods}

\section{Study Site}

Forest park is a 2,000 hectare natural area within the Portland, Oregon city limits, just northwest of downtown Portland (Figure 2). Elevation in the park ranges from approximately 20 meters to 300 meters above sea level and the terrain consists mainly of steep upland slopes that average between 15 and 30 percent grade, placing many sites at risk of landslides during the rainy season (McAllister et al., 2011). The region is characterized by a mild maritime climate with cool wet winters and warm dry summers (Broshot, 2011). Forested stands in the park are relatively homogenous in age (50-100 years old), and are composed of vegetation communities characteristic of second-growth forest of the Douglas-fir (Psuedotsuga menziesii), Western hemlock (Tsuga heterophylla) vegetation zone (Forest Park Conservancy and Forest Park Alliance, 2013.) Forest Park is a patchwork of conifer dominant, mixed conifer-deciduous, and deciduous dominant stands. Deciduous stands are concentrated in the middle portion of the park most impacted by the fires of 1940 and 1951 (Kuhn, 2005).

Four of the six long-term research sites established by the Dresner Lab and collaborators were included in this analysis (Figure 2; Figure 3). These plots are Balch, Audubon, Miller, and Burlington, and represent an urban mature, urban old-growth, rural mature, and rural old-growth site, respectively. Audubon is considered an urban oldgrowth site due to greater diversity of tree ages, presence of 150 to 200 year-old Douglasfir trees, and standing large 'snag' trees. There were no obvious signs of mass soil erosion or legacy logging roads at the site. Balch is considered the most 'degraded' urban 
site due to low diversity of tree species (Figure 3) and minimal sapling abundance, presence of a dense understory of ivy, legacy logging roads, and erosion 'slumps' (McDonald, 2011; Dresner et al., in review). Miller is a rural mature site, and although the canopy Douglas-fir trees are slightly younger than Balch (Mcdonald, 2011) Miller has been found to have a greater number of late-successional features, such as a diversity of tree ages, and greater abundance of shade tolerant conifers (Figure 3)(McDonald, 2011). Burlington, the fourth site, is outside the boundary of Forest Park, but sits on public land and is managed as an old growth preserve within the greater Forest Park Conservation Initiative. It similarly is characterized by a large diversity of tree ages, very large Douglas-firs (some as old as 300 years) and old, fire-scarred western red cedar trees. As late as 1991, the rural old-growth site was connected to Forest Park by contiguous mature forests, but recent clear-cut events on private land have disrupted this connectivity and Burlington plot is now surrounded by privately held Douglas-fir plantations (Broshot, 2011).

\section{Productivity Methodology}

During the field seasons of 2015-2016, we revisited the LTER plots 5 years after initial measurements were taken. We remeasured tree $\mathrm{DBH}$ for each living tree in the plot larger than $5 \mathrm{~cm}$. We noted ingrowth of saplings that have become larger than $5 \mathrm{~cm}$ since plot establishment, but there were so few young saplings that grew to this size in the 5year interval ( $\sim 1$ per plot) that they were not included in this analysis. For trees that have died in the past 5 years, we noted general features of the dead tree, including presumed 
cause, whether the tree was standing or supported, or whether it was on the ground as CWD.

Standard allometric equations (Jenkins et al., 2004) were used to quantify the biomass of each tree, at each measurement time. For each tree, the change in biomass was calculated by taking the difference between 5 year interval measurements. Some live trees were remeasured and showed negative growth. I assumed negative growth was more likely due to measurement error than the tree losing biomass while alive. For these trees, I instead assigned it the same DBH as its initial measurement. We did not measure diameter of dead trees, but I used their initial DBH to calculate biomass addition to the snag or CWD pool, depending on the main stem condition noted during field studies. The initial CWD estimates were based on a transect study performed during plot establishment. The transect study followed USFS protocol (Brown, 1974) using a $5 \times 100 \mathrm{~m}$ adjacent line transects at each $25 \mathrm{~m}$ interval.

For each plot, I calculated Net Primary Productivity of Boles (NPPB) (Acker et al. 2002)

- Net Primary Productivity of Boles (NPPB) $=[\Delta$ Biomass (living) + Biomass (dead) $]$

This measures the total change in biomass accumulated in living tissue during a time period. Studies estimate that living trees make up $40-70 \%$ of the total non-mineral soil carbon in a forest (Acker et al., 2002; Gray et al., 2016). Because Carbon (C) sequestration is proportional to biomass accumulation ( $\mathrm{C}$ makes up an average of $45-50 \%$ 
of tree tissue), $\mathrm{C}$ content and biomass of a forest are used interchangeably in the literature.

Plot productivity is based on biomass accumulation of all trees in a stand, and so this analysis essentially resulted in one overall value of stand productivity for each plot. To test for statistically significant differences in productivity related to an urban gradient, I sub-selected the largest canopy trees from each plot since these trees comprise a large share of the total biomass accumulation within each stand. I selected Douglas-fir trees with an initial diameter of $90 \mathrm{~cm}$ or more and compared their rate of biomass change over the 5-year interval, excluding trees that died over this time.

\section{Soil Methodology:}

National soil surveys for all sites indicate the same soil series, Goble silt loam (Web Soil Survey, 2017). Goble silt loams are Udic Inceptisols (Andic Frangiudepts) with an underlying fragipan layer at approximately 1 meter in depth. Natural Resources Conservation Service soil surveys (2017) suggest a typical $\mathrm{pH}$ of 5.6, and an organic matter content of $5.5 \%$ for the upper mineral soil layers of this soil series.

Each 1-hectare site had previously been subdivided into 25 meter x 25 meter subplots. I chose to sample soil at one location within each subplot for a total of 16 samples for each 1-hectare plot. For Balch and Audubon, I sampled just outside one of the four microplots (established to study herbaceous cover) within each 25 meter x 25 meter subplot (Figure 4). These microplots are regularly spaced, and I chose the same relative microplot in each subplot (the "A" labeled subplot) unless I was unable to find 
the microplot or if microplot fell on a skid road or eroding slope. In that case, I sampled in the nearest possible undisturbed location. I later chose to sample at the northeast corner post of each subplot within Miller and Burlington plots because of the difficulty of finding the microplot locations. For both sampling methods, the relative distance between sampling points (25 meters) was maintained (Figure 4).

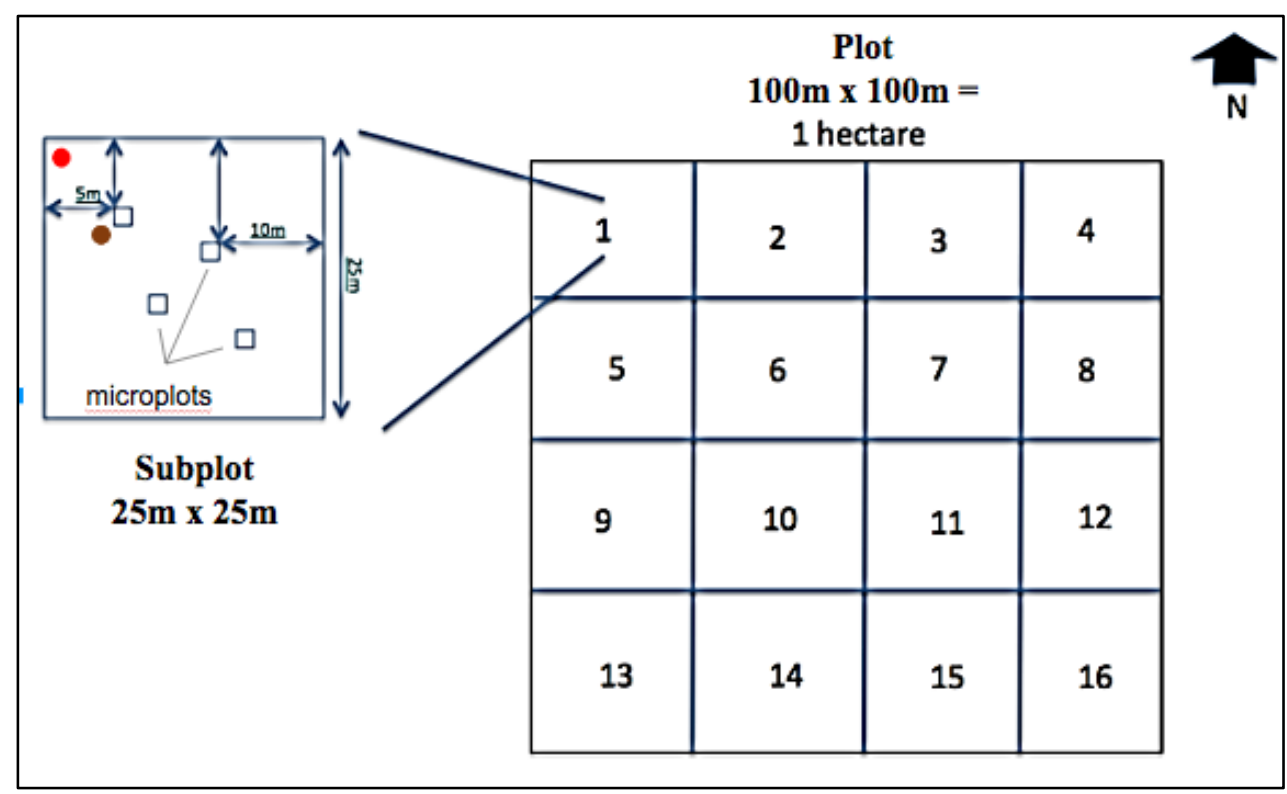

Figure 4: Layout of a 1-hectare research site subdivided into sixteen $25 \mathrm{~m} \times 25 \mathrm{~m}$ subplots by corner PVC posts. Within each subplot, 4 permanent microplots (1m $x 2 \mathrm{~m}$ quadrat of PVC piping) were previously established for monitoring ground vegetation. Soil samples were taken just outside of the northwest microplot in each subplot in Balch and Audubon sites (brown circle). Soil sampling was later adjusted to just inside the Northwest corner post for the Burlington and Miller plots (red circle). Figure adapted from Copp, 2014.

I sampled soil on four days in the winter/spring of 2016. All days were partly cloudy with high temperatures near $10^{\circ} \mathrm{C}$ following a day of moderate-to-heavy rain. At each sampling location I took 3 soil cores separated by $\sim 1 \mathrm{~m}$ using a 1" diameter soil tube, these samples were composited in the same bag, which was later homogenized. To extract the soil core, I cleared the litter-duff layer to expose the surface of the mineral 
soil. After extracting the top $\sim 20$ centimeters of mineral soil, I noted soil characteristics (color, consistency) and approximate slope and aspect of the sample location. The depth of surface horizons was measured with a ruler where a major soil horizon division (i.e., clay buildup and copper colored iron oxide granules) was apparent. In many cases, there was difficulty and subjectivity in determining a clear distinction between the $\mathrm{O}$ horizon and A horizon (Federer, 1982). Furthermore, the transition indicated by iron oxide granules and sticky clay accumulation most likely indicates the transition between A1 and $\mathrm{A} 2$ horizons, as the $\mathrm{A} 2$ is reported to begin around 24 centimeters deep and the Bw1 horizon begins at approximately 40 centimeters (Soil Survey Staff, NRCS). I did not have a soil core available to sample at these deeper layers to confirm these transitions.

The samples were refrigerated for up to three days before soil analysis began. For each subplot soil sample, soil organic matter was determined through loss-on-ignition (LOI) of $10 \mathrm{~g}$ oven-dried and sieved samples. The $\mathrm{pH}$ of a $30 \mathrm{ml}(\sim 10 \mathrm{~g})$ soil sample was measured in 1:1 deionized water using a $\mathrm{pH}$ probe. These methods followed the standard procedures of Kalra and Maynard (1991).

\section{LiDAR Methodology:}

LiDAR data was originally acquired in 2014 by WSI Applied Remote Sensing and Analysis for the Oregon Department of Geology and Mineral Industries. It covers the metropolitan region of Portland, and was available in shared folders on the Portland State University Network. The LiDAR acquisition used a 190-198 kHz single pulse, and averaged over 8 pulses per square meter. LiDAR point clouds were clipped within the geographic boundaries of the permanent research plots detailed earlier in this report 
(Balch, Audubon, Miller, and Burlington) I also included a 5th plot, Coyote, which is another urban mature plot that is similar in many compositional features to our most impacted urban mature plot, Balch (Dresner et al., in review).

I digitized the boundaries for each plot using ArcGIS (Version 10.4, ESRI), and I also randomly generated 41 additional square 1-hectare sample plot boundaries within the boundary of the park on ArcGIS (Figure 5). All plots were within management areas of the park where old-growth mixed conifer forest is a desired future condition, as determined by park managers (McCallister et al., 2011). I began with 60 random plots in stands characterized as Douglas-fir - Western hemlock forest alliance, or Douglas-fir giant forest alliance (a small set of sites that have very large Psuedotsuga and a greater degree of old-growth conditions due to limited logging disturbance prior to park establishment). Because there is a greater proportion of land area with the desired future state classified as Douglas-fir - Western hemlock forest in the rural segment of the park (McCallister et al., 2011), random plot locations yielded far more rural plots than any other type. Out of 60 randomly generated plots, I manually "thinned" some of the plots that were in very close proximity to other plots to achieve a more balanced sample pool. I then classified each plot as "Urban", "Mid", "Rural", along the boundaries used by Broshot (2011). In the case of plots in the giant forest alliance, or in the property on property adjacent to Burlington, as well as Burlington and Audubon themselves, I considered these sites representative of "Old Growth" in Forest Park. I ended with 41 randomly located 1-hectare plots and 5 LTER plots for a total of 46 sample areas. 


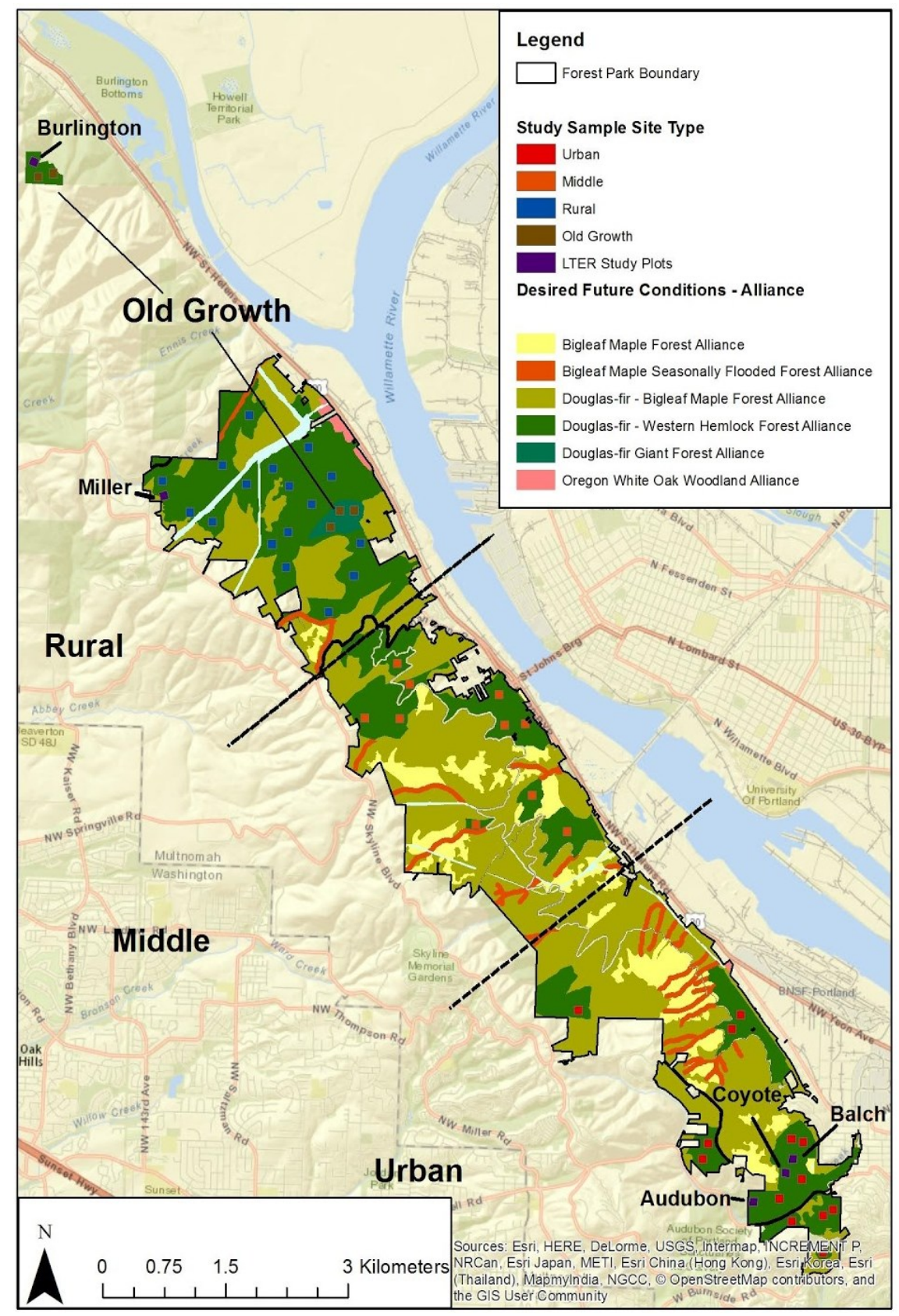

Figure 5: Location of 41 GIS generated random sample plots within Forest Park, as well as 5 LTER study plots. There were 46 total plots used to sample LiDAR point cloud data. I also investigated LiDAR metrics for 5 of the 6 LTER plots (shown in purple). Plots were classified based on relative proximity to the urban core, in three categories, urban, middle, and rural. Additionally, plots near the rural old growth LTER plot (Burlington) and in a small area of old growth in the rural end of the park were classified as "old-growth". Areas of deep green on the map represent areas of the park being managed to develop late-successional Douglas-fir - Western hemlock forest (McAllister et al., 2011). 
I clipped LiDAR .lda source files and a digital elevation model covering each of these sample areas using ArcGIS and then imported the LiDAR data for visualization and further analysis using FUSION software. FUSION software is a free and widely used tool produced by the US Forest Service. It can display and extract LiDAR-based canopy metrics from LiDAR point clouds (McGaughey, 2009). I specifically used the CloudMetrics and CanopyModel processing programs available within the Fusion software package. Out of the large number of metrics calculated using this software, I selected 8 descriptive parameters of the LiDAR point cloud (excluding points below 8 feet to filter out ground and shrub vegetation) (Figure 6). These parameters include, 95th percentile height, 90th percentile height, and 75th percentile height. elevation standard deviation, canopy cover ( $\%$ of returns above 8 meters), canopy rumple, and coefficient of variation of elevation (standard deviation of elevation/ mean of elevation). This set of parameters has been shown to predict plot-level structural patterns (Kane et al, 2000a; Sheridan et al., 2015, Yu et al., 2006). Absent from this list is maximum elevation, as this measure can be susceptible to outlier data points, and is not as reliable as the 95th percentile height for describing the general maximum height class of canopy trees in a plot (Naesset \& Gobbaken, 2005). Both Rumple and standard deviation of elevation are key values that relate to the heterogeneity of the canopy surface, and are thus good estimates of canopy structure. Rumple is calculated by generating a surface model of canopy height and comparing its surface area to the ground surface area (Kane et al., 2010a). 


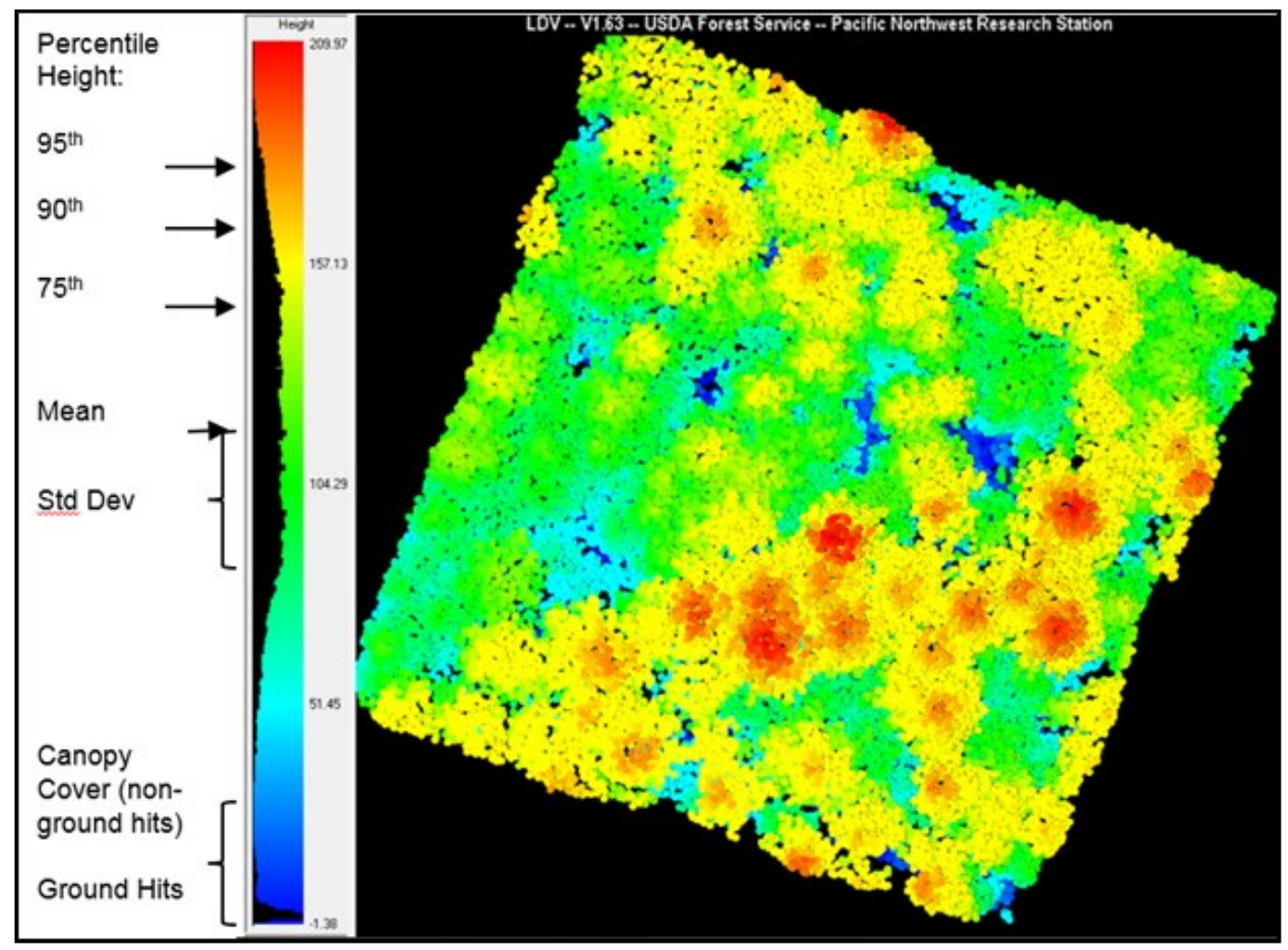

Figure 6: Example 3D LIDAR rendering using Fusion visualization software showing Burlington Plot (Rural old-growth). Side histogram represents height of first return LiDAR data point. LiDAR point cloud metrics that were extracted for each of 46 plots and used for comparative analysis are represented in the histogram side-bar. All height measurements are in feet, as this was the value measured in the source .las files. Histograms and color displays are standardized to represent height above ground surface.

\section{Statistical Analysis}

All data was organized using Excel. Statistical analysis and tests were performed using R (version 3.3.2). For all comparisons between plots, data was tested to determine if it met the assumptions of independence, normality and equal variance. To determine independence, I examined each parameter for spatial autocorrelation using a Moran's I test (i.e., I determined if each sample was influenced by its proximity to other samples). To determine if the data were normally distributed I used a Shapiro-Wilks test. To 
determine if the data had equal variance I used a Bartlett test. If the data for each parameter met the assumptions I then performed an Analysis of Variance (ANOVA) and Tukey post hoc analysis. ANOVA allowed us to examine whether a significant difference exists between independent parameters between comparison sites and the Tukey post hoc analysis revealed the pairwise means that were significantly different from others.

For LiDAR data, Pearson correlations between each LiDAR variable were calculated, and distributions of the values were compared across location classes using either ANOVA (when the distribution was normal) or Kruskal-Wallis tests (when not normal). Because LiDAR metrics are numerical and are generally linearly correlated with each other, they are also well suited for principal component analysis (PCA) (Kane et al., 2010a). I normalized each LiDAR metric by finding its z-score distribution. I then fed these values into a PCA and plotted the bi-plot across location classifications. For comparative analysis of LiDAR metrics across an urban-rural gradient, Balch and Coyote were considered "Urban", Miller was considered "Rural", and Audubon and Burlington were considered "Old Growth". 


\section{Results}

\section{Net primary productivity}

Net primary productivity of tree boles (NPPB) for each plot ranged from 6.8 10.7 Mg/(ha*yr) (Figure 7; Table 2). This estimate includes the biomass of living trees as well as the biomass of newly dead trees. The total biomass for the plots after 5-years ranged from 455.7 - 708.4 Mg/ha, within reported ranges from other studies (Acker et al., 2002 Smithwick et al.,2002. Janisch and Harmon 2002). Our old growth plots had the highest biomass both at initial measurement and after 5 years, as expected based on their older stand age. Miller appears to have lower overall biomass than Balch, likely reflecting that its oldest trees are on average 5-10 years younger than Balch (McDonald, 2011; Dresner et al., in review). Trends in NPPB ranged from 6.8-10.7 Mg/ha* Yr, with Balch gaining the most biomass, and Audubon the least.

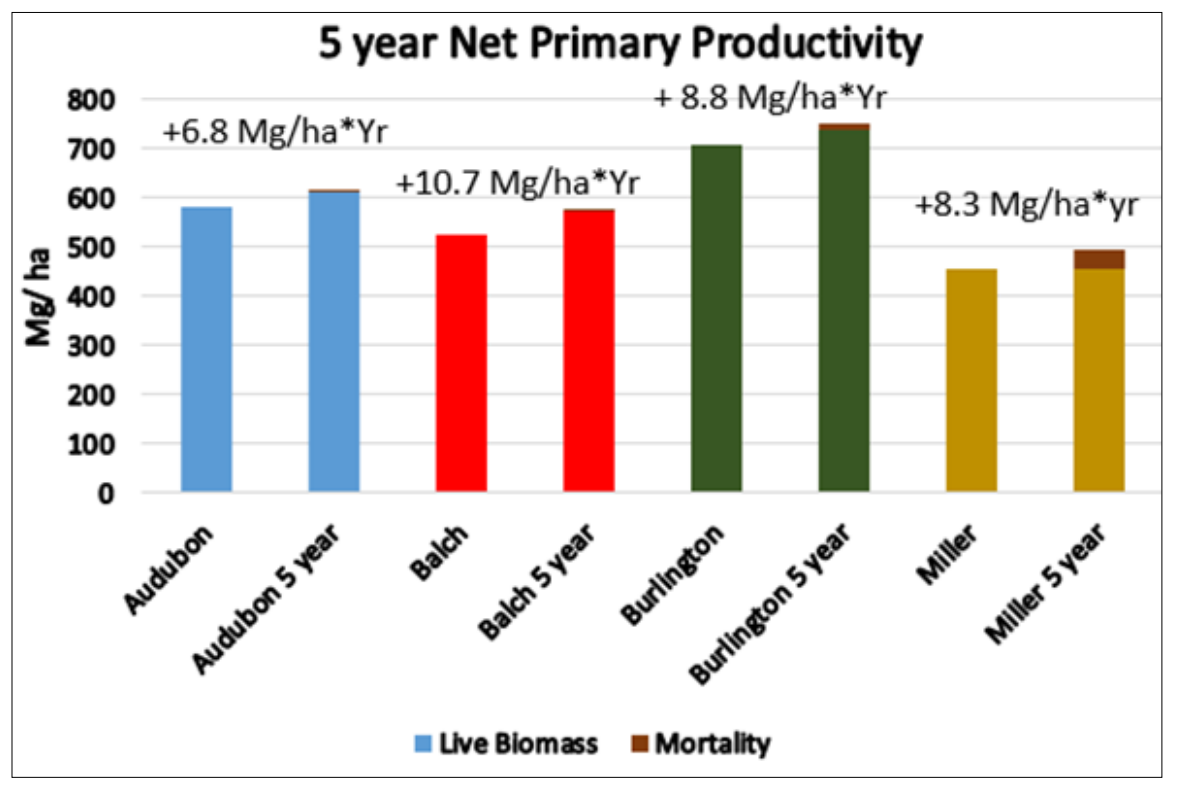

Figure 7: Net Primary Productivity of Tree Boles (NPPB) for each plot at plot establishment (20102011) and at 5 years (2015-2016). NPPB is a measure of the amount of biomass stored in a system over time. Mortality was considered part of NPPB in this measure to account for total biomass added to the system over time. 
Growth data from the largest canopy Douglas-firs in each plot (Table 3) revealed that individual tree growth was not stunted due to urban proximity. Plots differed significantly in individual tree biomass accumulation $(\mathrm{p}<0.05$. Mature plots, Balch and Miller, had higher growth rates than old-growth plots, $\mathrm{p}<0.05$ ); Balch had the highest growth rate of all (Balch $\mathrm{p}<0.001$, Tukey HSD) (Table 3, Figure 8). Large trees in Balch had higher growth rates over the 5 year period $(12.9 \%)$ than the other plots.

Table 2: Biomass change in each plot. All values (except percent change) are in $\mathrm{Mg} /(\mathrm{ha}$ * yr)

\begin{tabular}{|l|l|l|l|l|l|}
\hline Plot & & Audubon & Balch & Burlington & Miller \\
\hline Live Biomass Initial & & 582.1 & 525.9 & 708.4 & 454.0 \\
\hline Live Biomass 5 Year & & 613.8 & 573.9 & 738.6 & 455.7 \\
\hline $\begin{array}{l}\text { Total Change in live } \\
\text { biomass }\end{array}$ & 31.7 & 48.1 & 30.2 & 1.7 \\
\hline $\begin{array}{l}\text { Change in live biomass } \\
\text { (per year) }\end{array}$ & 6.3 & 9.6 & 6.0 & 0.3 \\
\hline $\begin{array}{l}\text { Percent change } \\
\text { Dead Biomass 5 year }\end{array}$ & 2.4 & 5.5 & 14.0 & 40.1 \\
\hline $\begin{array}{l}\text { Dead Biomass input per } \\
\text { year }\end{array}$ & 0.5 & 1.1 & 2.8 & 8.0 \\
\hline Total NPPB & 6.8 & 10.7 & 8.8 & 8.3 \\
\hline
\end{tabular}


Table 3: Biomass change for Canopy Douglas-fir in each plot $>90 \mathrm{~cm}$ DBH. Mean is reported (standard deviation in parentheses).

\begin{tabular}{|c|c|c|c|c|}
\hline Plot & Audubon & Balch & Burlington & Miller \\
\hline $\begin{array}{l}\text { Number } \\
\text { PSME }>90 \mathrm{~cm}\end{array}$ & 29 & 16 & 33 & 16 \\
\hline $\begin{array}{l}\text { Average of DBH } \\
\text { in } \mathrm{cm}\end{array}$ & $\begin{array}{l}113 \\
(17.8)\end{array}$ & $\begin{array}{l}98.3 \\
(8.1)\end{array}$ & $\begin{array}{l}111.9 \\
(15)\end{array}$ & $\begin{array}{l}101.8 \\
(10.9)\end{array}$ \\
\hline $\begin{array}{l}\text { Average of } \mathrm{DBH} \\
5 \text { year }\end{array}$ & $\begin{array}{l}115.1 \\
(17.4)\end{array}$ & $\begin{array}{r}103.2 \\
(8.2)\end{array}$ & $\begin{array}{l}114.6 \\
(15)\end{array}$ & $\begin{array}{l}105.2 \\
(11.4)\end{array}$ \\
\hline $\begin{array}{l}\text { Average } \% \text { change / } \\
\text { tree }\end{array}$ & $\begin{array}{l}2.0 \% \\
(1.7 \%)\end{array}$ & $\begin{array}{l}5.1 \% \\
(1.4 \%)\end{array}$ & $\begin{array}{l}2.4 \% \\
(1.3 \%)\end{array}$ & $3.3 \%(1.1 \%)$ \\
\hline $\begin{array}{l}\text { Total Biomass in } \\
\mathrm{Mg}\end{array}$ & $\begin{array}{l}11.36 \\
(4.95)\end{array}$ & $\begin{array}{l}8.02 \\
(1.77)\end{array}$ & $\begin{array}{l}11.18 \\
(4.19)\end{array}$ & $\begin{array}{l}8.80 \\
(2.59)\end{array}$ \\
\hline $\begin{array}{l}\text { Total Biomass } \\
5 \text { year }\end{array}$ & $\begin{array}{l}11.80 \\
(4.99)\end{array}$ & $\begin{array}{l}9.05 \\
(1.92)\end{array}$ & $\begin{array}{l}11.82 \\
(4.27)\end{array}$ & $\begin{array}{l}9.54 \\
(2.868)\end{array}$ \\
\hline $\begin{array}{l}\text { Average } \% \text { biomass } \\
\text { change }\end{array}$ & $\begin{array}{l}5.0 \% \\
(4.4 \%)\end{array}$ & $\begin{array}{l}12.9 \% \\
(3.6 \%)\end{array}$ & $\begin{array}{l}6.1 \% \\
(3.2 \%)\end{array}$ & $8.4 \%(2.9 \%)$ \\
\hline
\end{tabular}




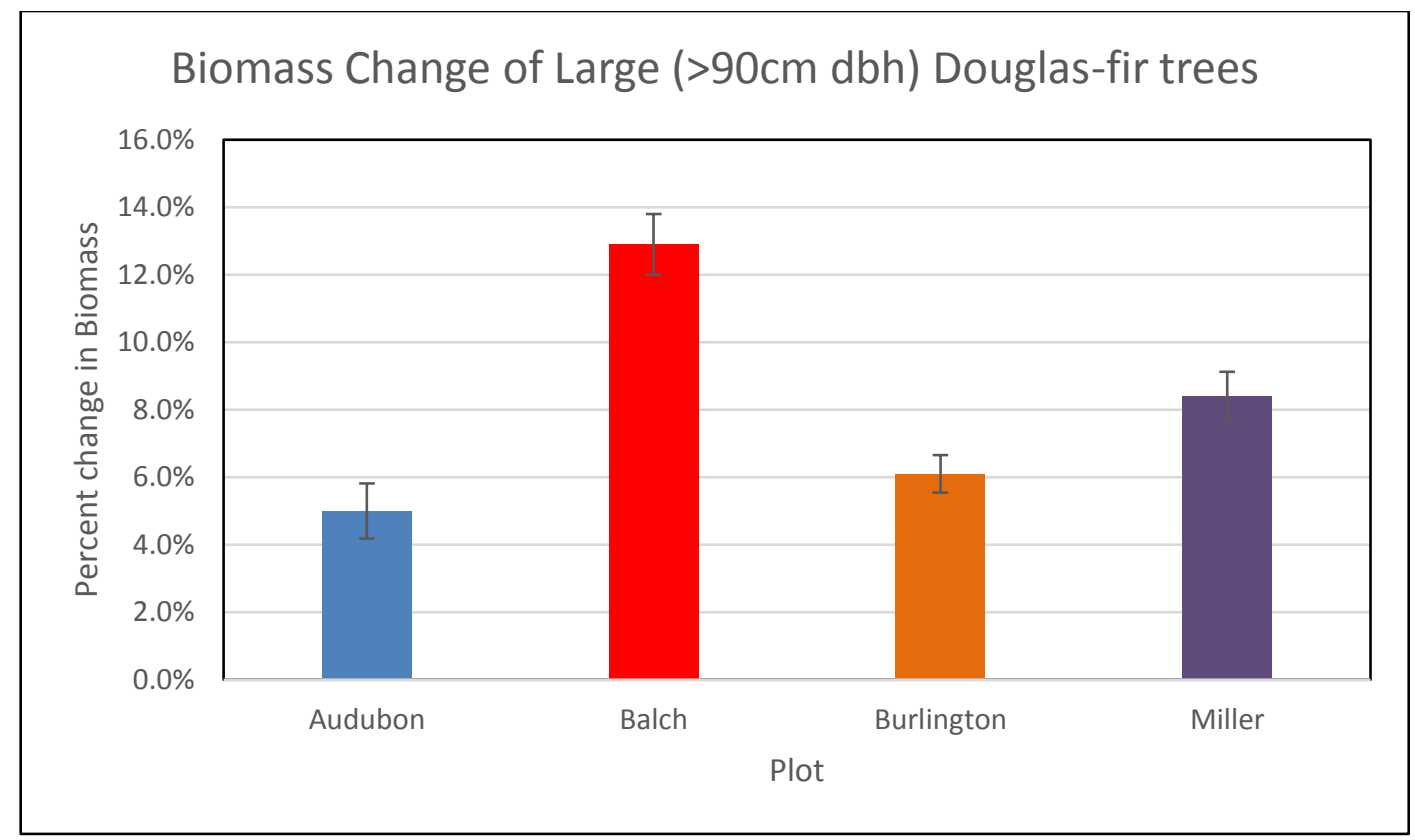

Figure 8: Biomass change of Large $(>90 \mathrm{~cm})$ Douglas-fir Trees over 5 year period. Error bars show standard error.

\section{Mortality}

There was a large difference in mortality patterns across plots. Miller, the rural mature plot, had the highest degree of mortality, both by number and by average size of dead trees. Treefall was the most common cause of mortality across plots (Figure 9). While wind blowdown was the suspected cause in nearly all cases, it is also likely that winter ice storms may have also contributed to treefall death. Miller plot had a large instance of treefall mortality, causing death to several mid-large sized canopy Douglas-fir and big-leaf maple. Underlying subcanopy trees were also crushed or destabilized by fallen trees. Burlington had a large number of treefall events as well. There was also a substantial number of tree deaths in small tree classes that were caused by the recent addition of a hiking trail coursing through portions of the plot. The urban plots, Audubon 
and Balch, had less mortality overall, with Balch having the fewest number of dead trees after 5 years. Suppression/competition related death were a contributor to tree mortality across plots (Figure 9), but were highest relative to other causes in Balch, where a few sub-canopy deciduous trees died of suppression, and almost no large trees were blown over. The mortality of all conifers was highest in the rural plots mainly due to the impact of blowdown (Figure 10), but susceptibility to both treefall and suppression mortality may have been indirectly related to increased competition from the high number of trees present.

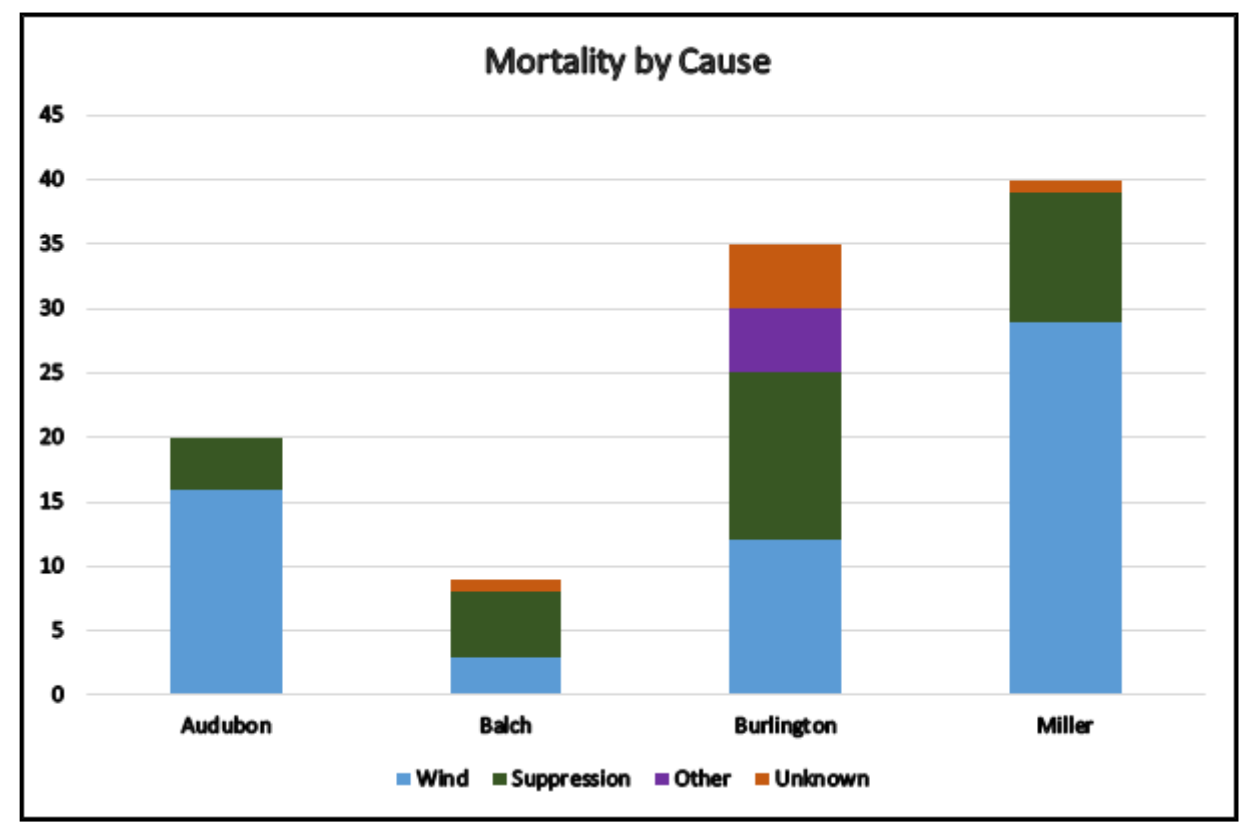

Figure 9: Causes of Mortality in each plot. "Other" is generally related to the impact of trail building in Burlington Plot over the summer of 2016. Several small and mid-sized trees were cleared for trail building. "Wind" indicates any treefall death, although ice could not be ruled out as a proximate cause for tree fall. 


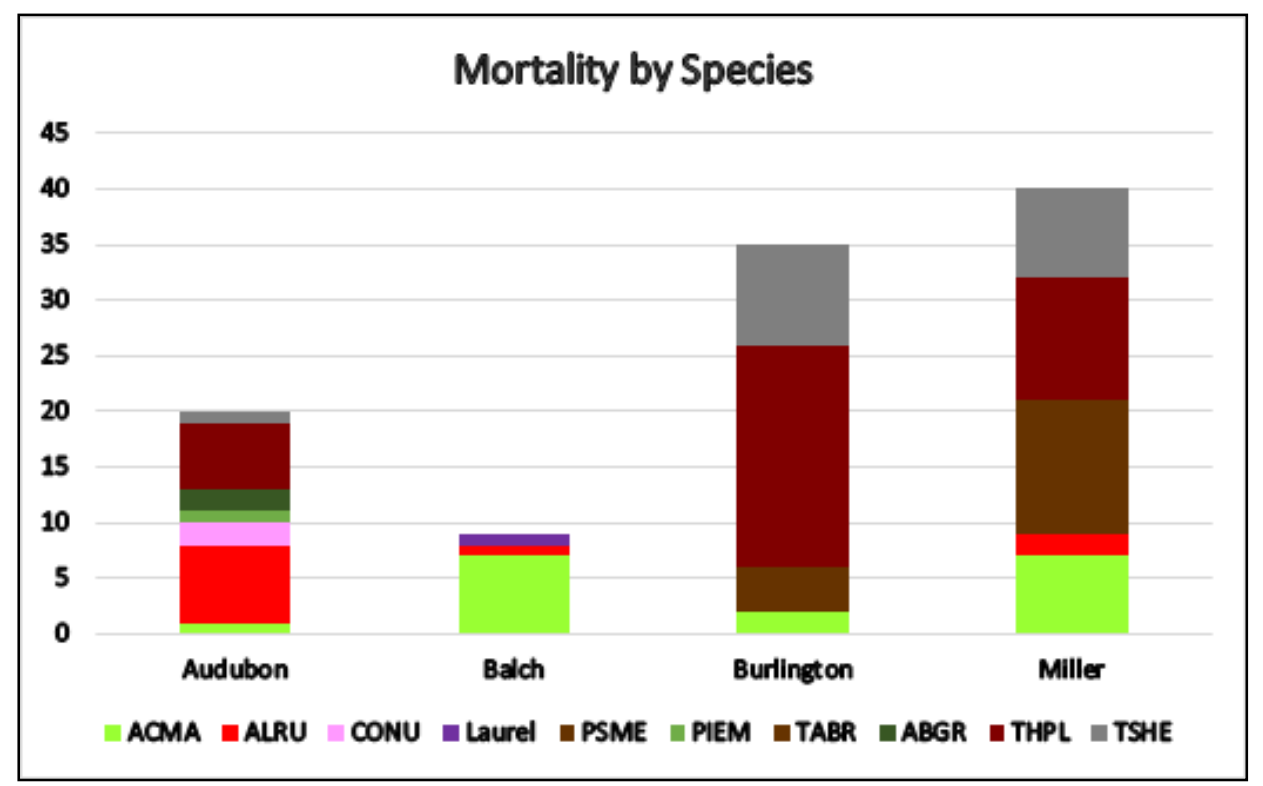

Figure 10: Mortality by species

\section{Coarse Wood}

The input of CWD in the past 5 years differed substantially between plots due to the large difference in mortality rate. Miller had a large increase in CWD $(40.1 \mathrm{Mg} / \mathrm{ha})$ while Balch saw relatively little gain in CWD. CWD was already lacking at the Balch site in the initial CWD survey and was greater at all other sites. Initial CWD was already lowest in Balch (12.9 Mg/ha, se: \pm 1.64$)$ and greatest in Miller (41.8 Mg/ha se: \pm 4.6$)$ (Figure 11). The disparity between plots appears to be heightened after 5 years. Because of differing methodology in assessing CWD at plot establishment and 5-years, the amount of CWD reported for these plots should be considered as tentative. 


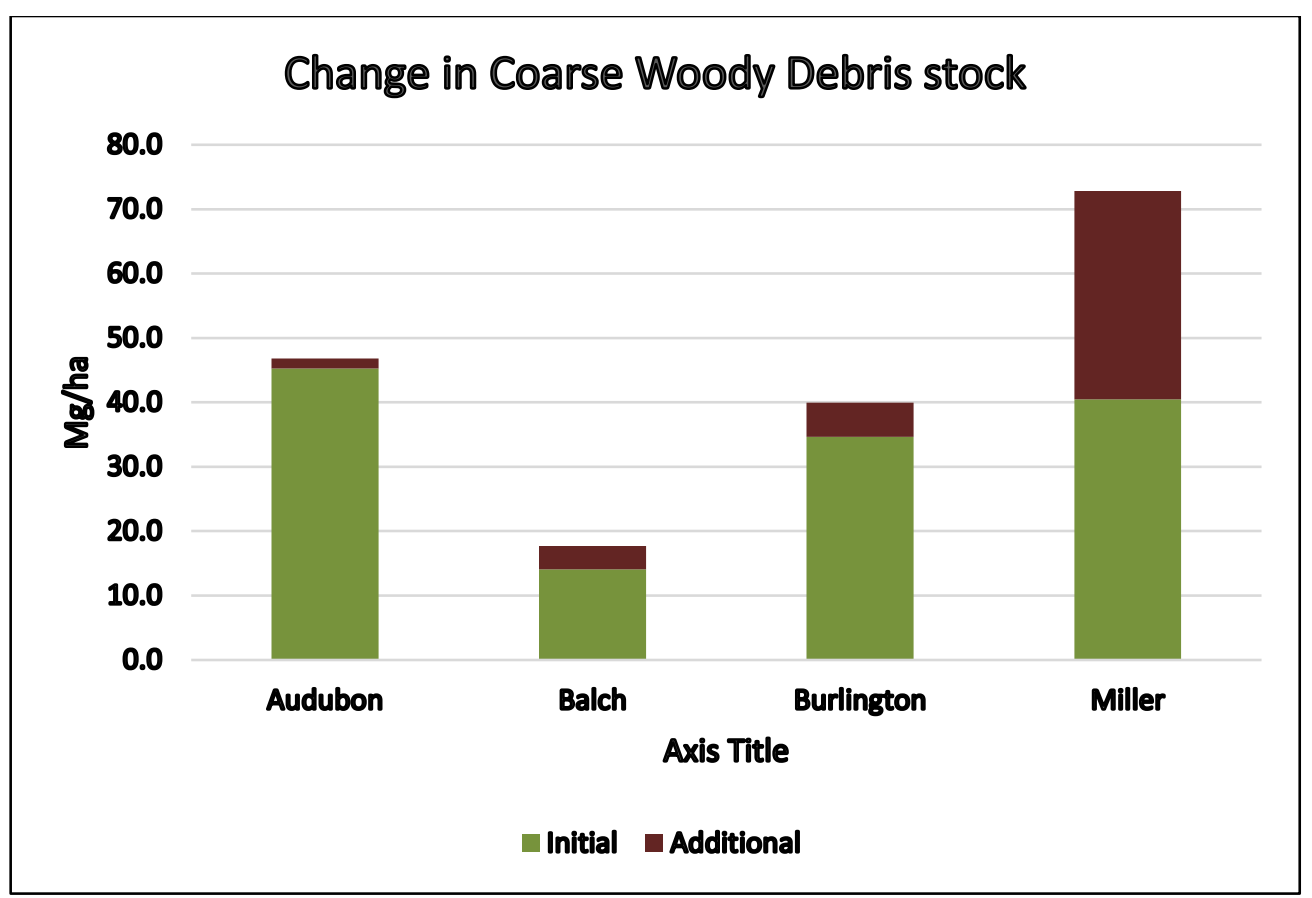

Figure 11 Change in Coarse Woody Debris stock over 5 years, by plot.

\section{Soil}

Soil parameters varied between the sites, notably at the Balch (urban mature) site. Balch had the highest mean soil $\mathrm{pH}(5.87$, se: \pm 0.06$)$ and was significantly higher than all other sites (ANOVA, $\mathrm{F}=25.2, \mathrm{p}<0.05$; Tukey post-hoc analysis $\mathrm{p}<0.05$ for each site, Figure 12). $\mathrm{pH}$ values were not spatially autocorrelated (Moran's I p > 0.05), and were normally distributed across all sites (Shapiro-Wilk test, $\mathrm{W}=0.98, \mathrm{p}=0.29$ ), with equal $\operatorname{variance}(\mathrm{F}=0.43, \mathrm{p}=0.11)$.

Soil OM, however, was not significantly different between sites (ANOVA, $\mathrm{p}=$ 0.12, Figure 13). I determined that the OM values were not spatially autocorrelated (Moran's I $\mathrm{p}>0.05$ ). The original data were not normally distributed but this was corrected with log transformation. Log transformed data met the normality and equal 
variance assumptions (Shapiro-Wilk test, $\mathrm{W}=0.97, \mathrm{p}=0.24$, F-ratio test, $\mathrm{F}=0.66, \mathrm{p}=$ $0.43)$.

O/A horizon values were spatially autocorrelated (Moran's I $\mathrm{p}<0.05$ for all sites) and could not be analyzed with ANOVA analysis. Nevertheless, the O/A horizon showed trends similar to OM, lower in Balch and Burlington than in Miller and Audubon (Figure 14.)

All three soil parameters (OM, O/A depth, and $\mathrm{pH})$ were tested for correlation with slope and aspect at the sample location. The correlation was near zero in all cases, suggesting that slope and aspect of sample location were not significant confounding factors.

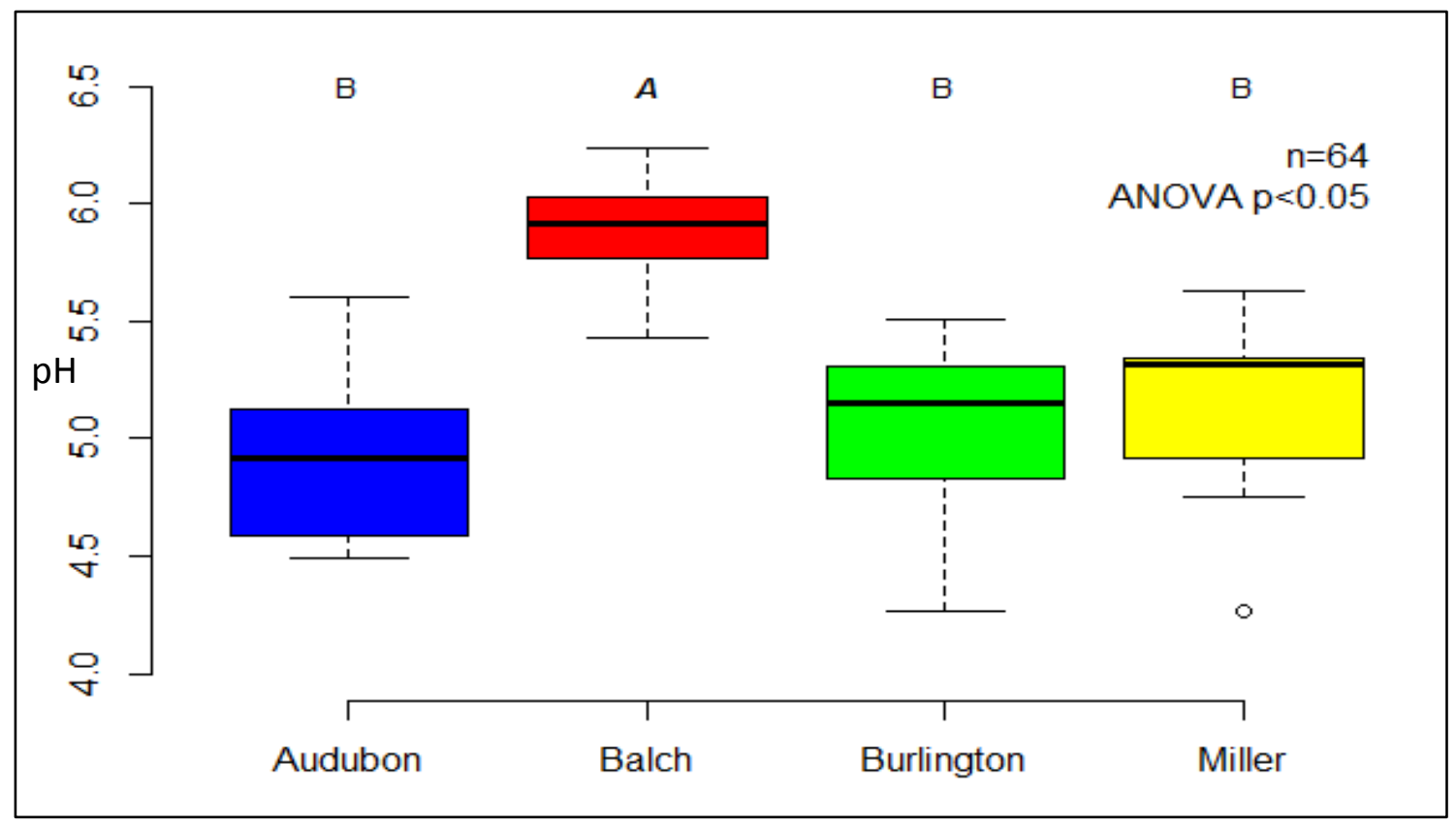

Figure 12: Boxplots of soil $\mathrm{pH}$ values from four sites in Forest Park. $\mathrm{pH}$ in the Balch site was significantly different than Audubon, Burlington, and Miller (ANOVA, $F=25.2, p<0.05$; Tukey post hoc analysis $\mathrm{p}<0.05$ for each site). Audubon, Burlington, and Miller were did not significantly differ from one another. 


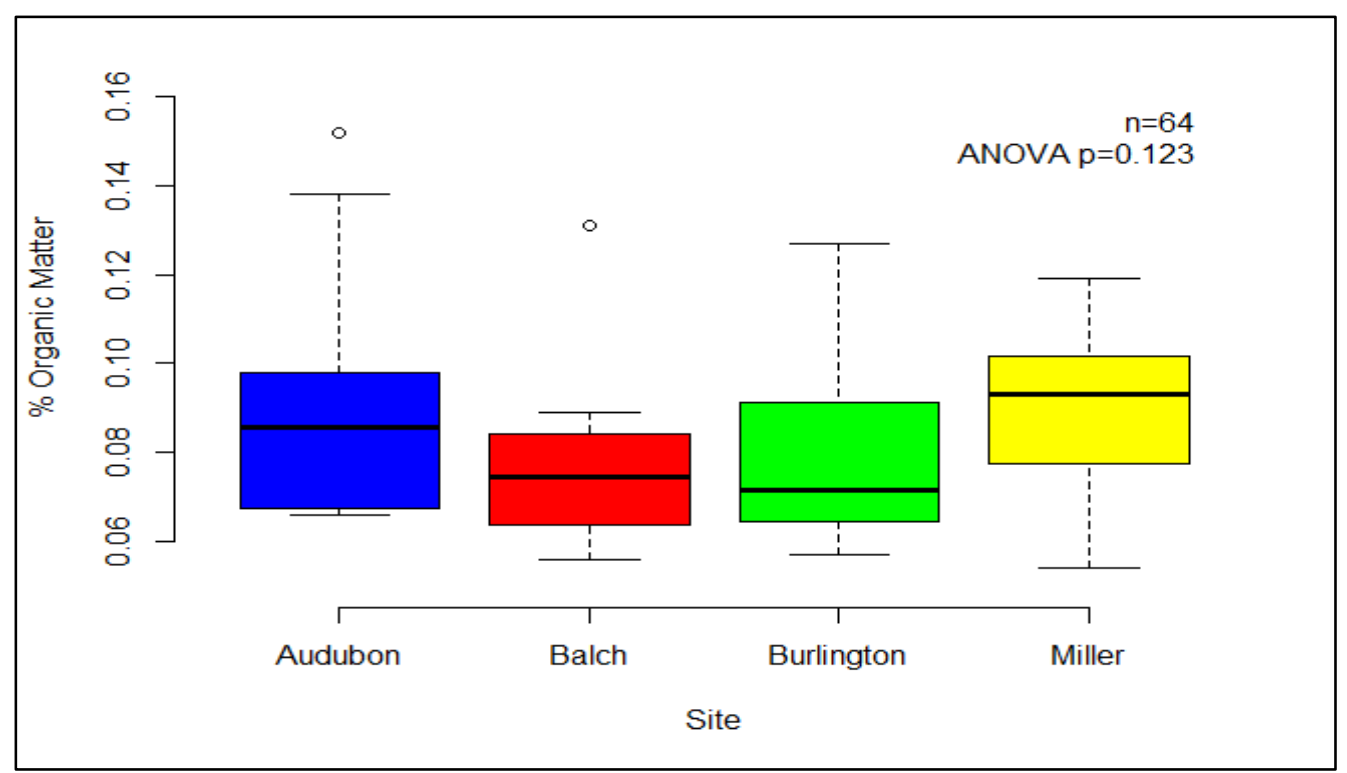

Figure 13: Boxplots of the percentage of organic matter in soil at four sites in Forest Park. The percentage of organic matter in each site did not significantly differ (log transformed data, ANOVA, $F=2.01, p=0.12$ ).

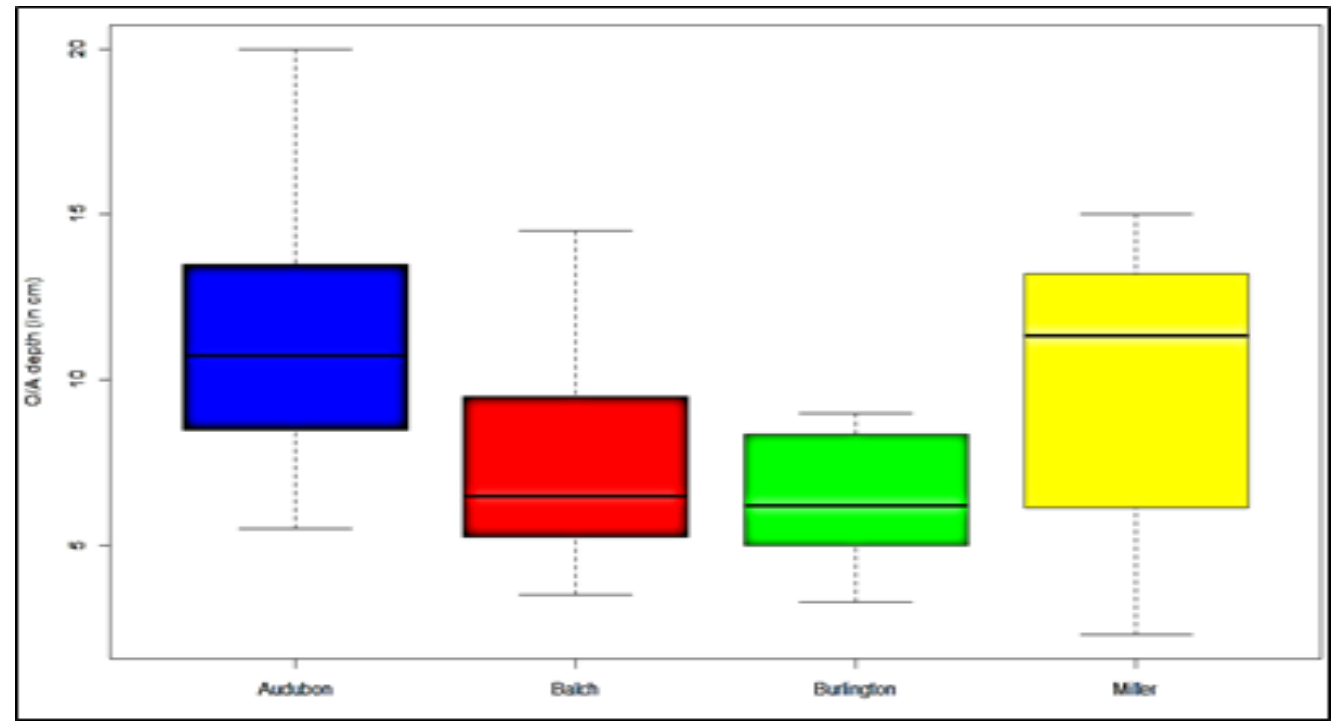

Figure 14: Boxplots of $\mathrm{O} / \mathrm{A}$ depth measured in four sites in Forest Park. Because depth measurements showed a significant spatial autocorrelation, ANOVA tests were not run on this data.

\section{LiDAR Results:}

Canopy LiDAR metrics differed significantly across groups. Elevation height metrics, which indicate the size (and generally the age) of the largest trees, showed a 
trend of old growth plots having canopy trees with the highest height, and rural plots having canopy trees with the lowest height (Table 4). Urban and mid plots were comparable, having intermediate height ranges. Old growth plots had significantly greater 95th percentile height than rural plots $(50.24 \mathrm{~m}$ vs $43.89 \mathrm{~m}$ respectively; $\mathrm{p}<0.01$, ANOVA, Tukey; see Table 4, Figure 15).

LiDAR metrics related to canopy structure (Figure 16), such as rumple, standard deviation of height, and coefficient of variation of height, revealed that old growth plots had significantly greater variability in height metrics than all other plots, and middle plots had greater structural heterogeneity with respect to urban and rural plots. The standard deviation of height (an indication of canopy structure) was greatest in old growth plots compared to all other sample plots ( $\mathrm{p}<0.01$, ANOVA, Tukey, Table 4), as was Rumple, the other canopy structure variable ( $p<0.01$, Kruskal, Kruskal-Nemenyi; Table 4, Figure 16). Canopy rumple statistics did not meet assumptions of normality and equal variance, and so were tested using nonparametric tests.

LiDAR statistics for each permanent research plot generally fell within the range of values of their respective location class (urban, rural, old growth) (Table 4, Figure 15, Figure 16). This indicates that the research plots demonstrate the expected canopy features representative of conifer-hardwood stands in their respective sections of the park. 


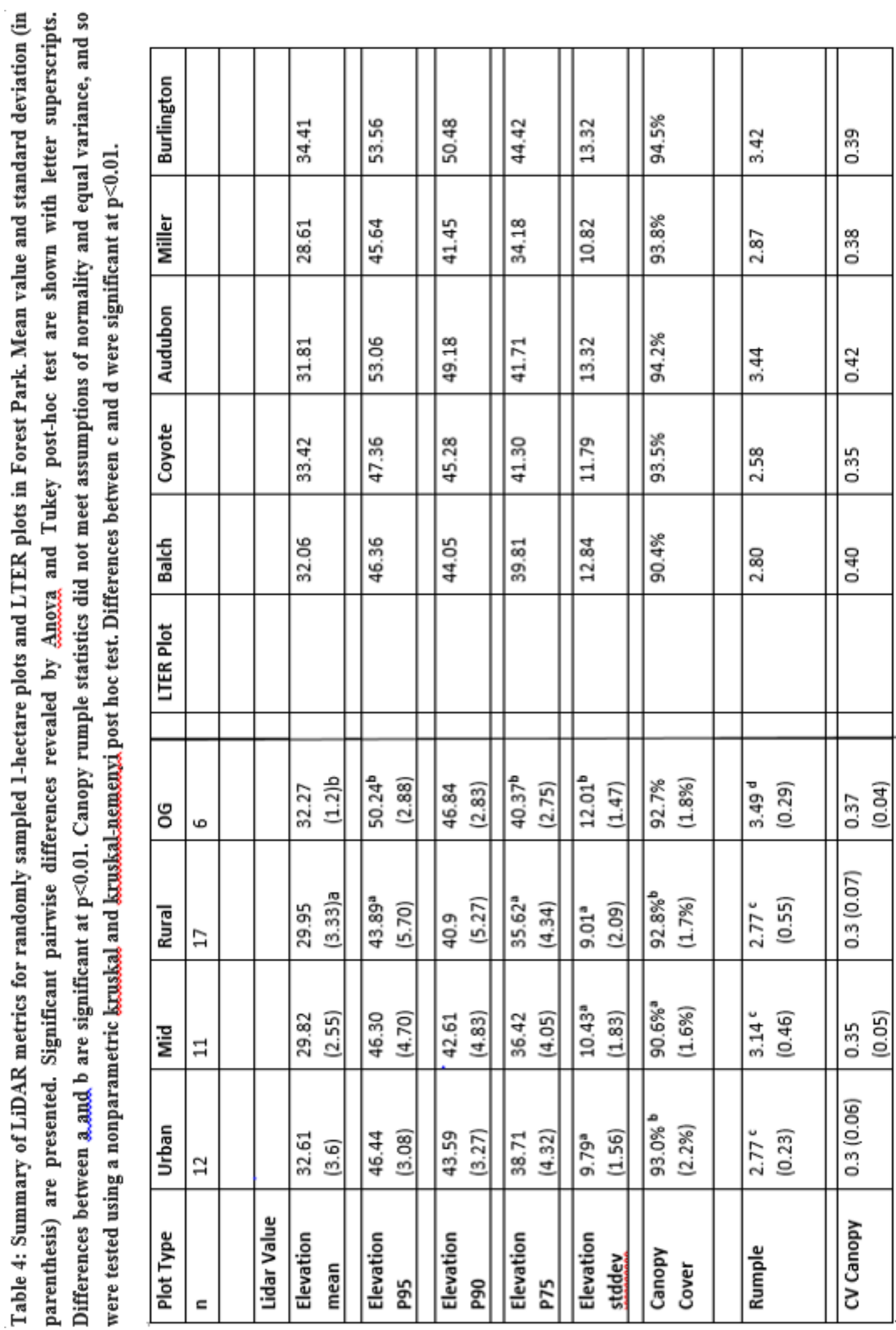




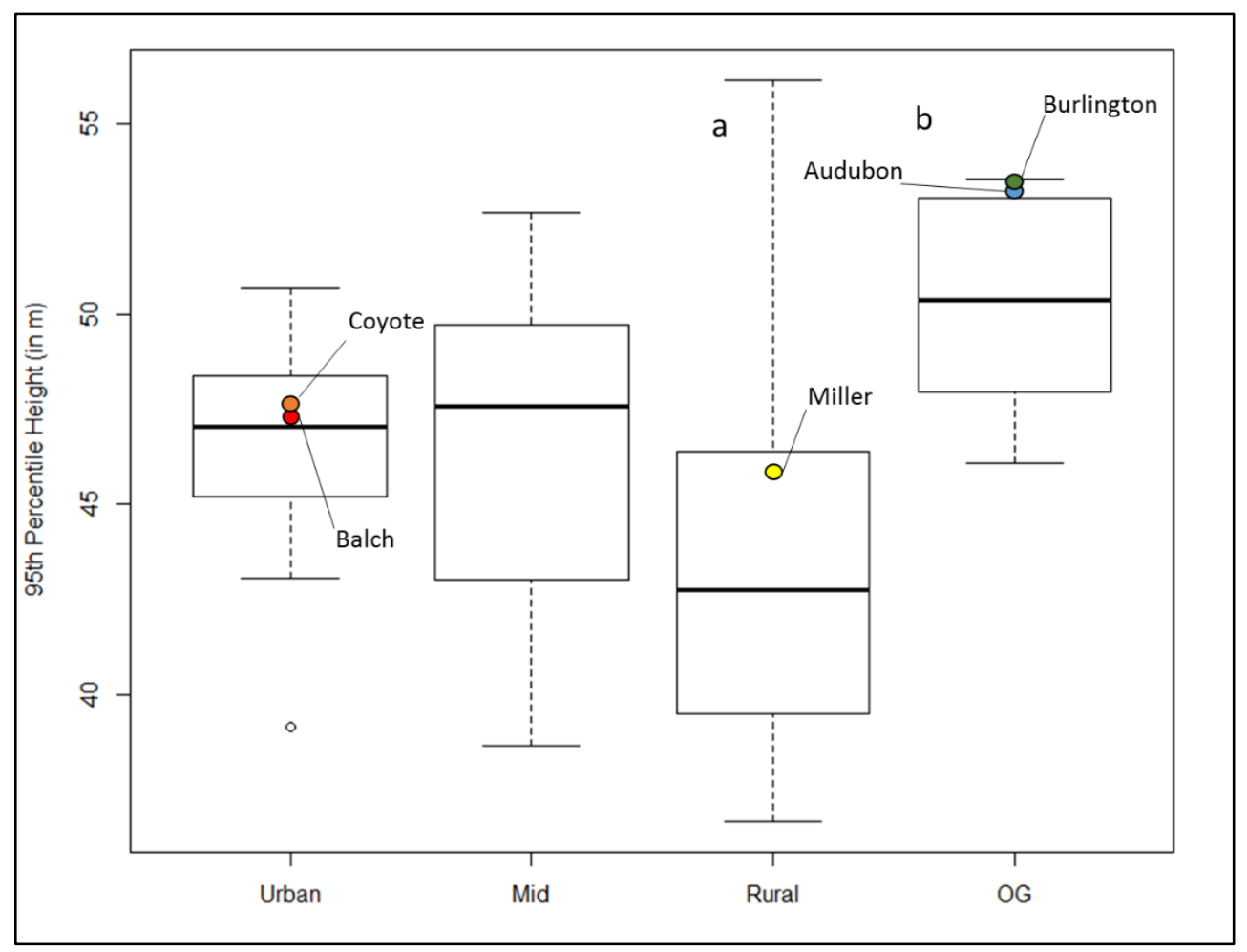

Figure 15: Boxplot 95th Percentile height of all 46 sample areas used in the LiDAR analysis. Data points for LTER plots are superimposed on these boxplots.

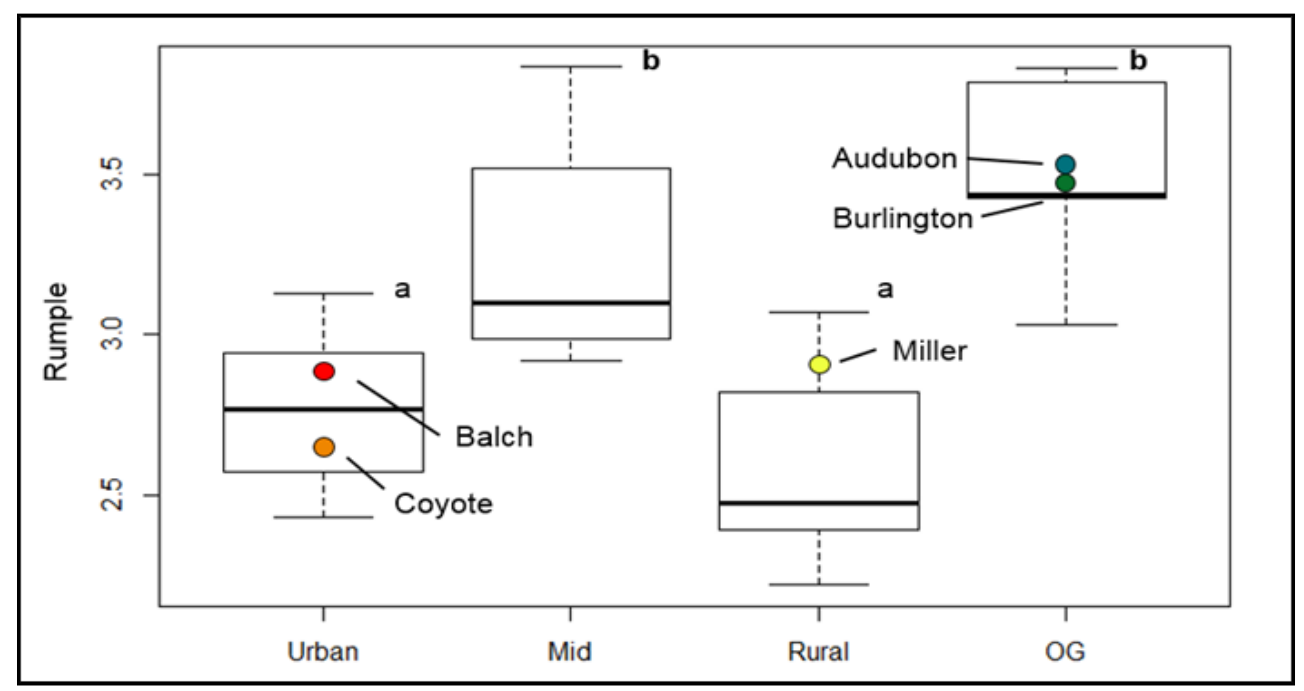

Figure 16: Boxplot of canopy rumple for all 46 sample areas used in the LiDAR analysis. Data points for LTER plots are superimposed on these boxplots. Higher rumple is an indicator of greater structural complexity of the canopy surface. 


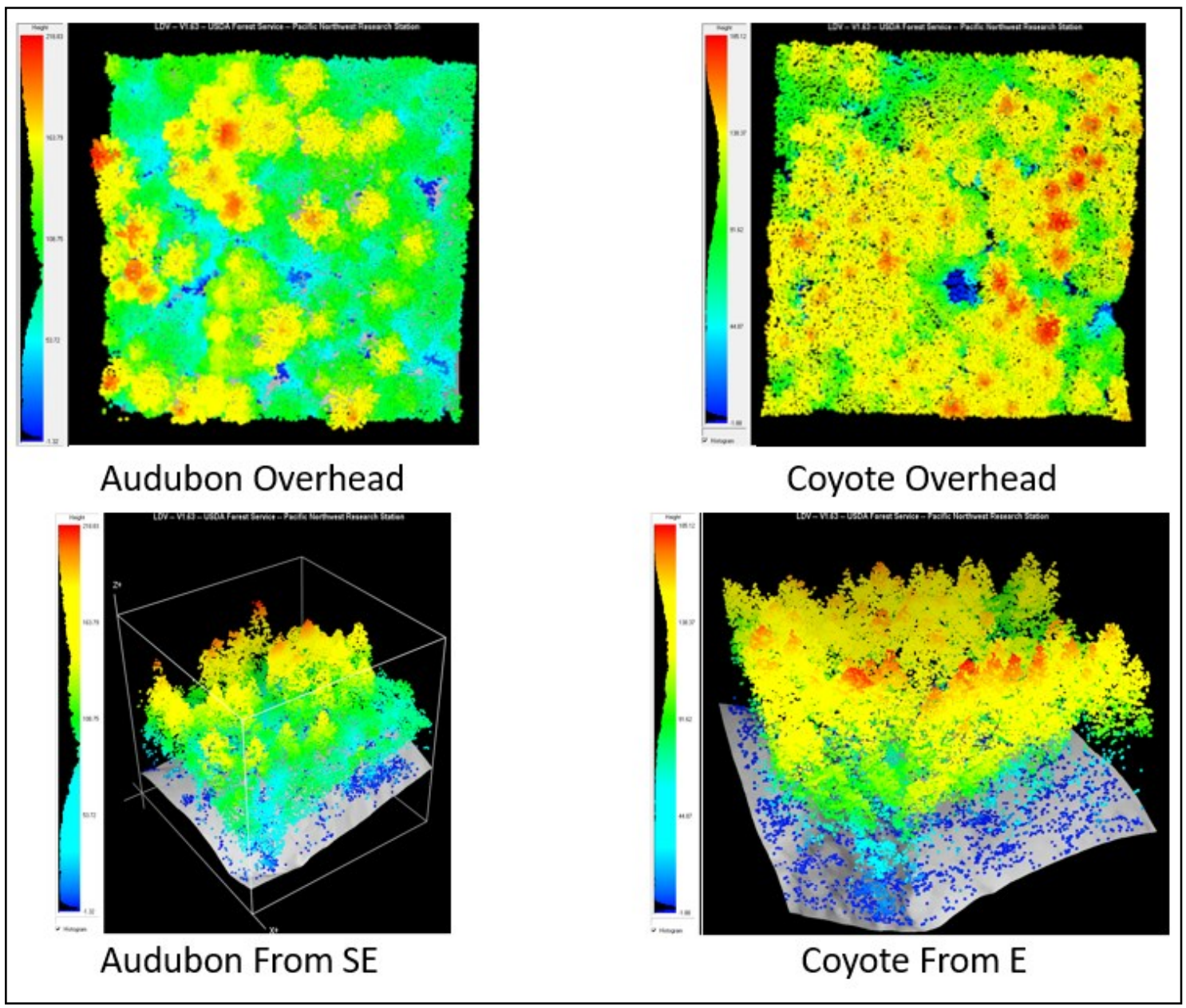

Figure 17: 3D LIDAR rendering of Audubon Plot (urban old-growth) and Coyote (Urban mature) using Fusion visualization software. These two plots had the greatest degree of difference in rumple of all LTER plots. This can be seen as a relatively homogenous canopy surface with few gaps in Coyote. All overhead views are oriented with North pointing toward the top of the image. All side images are rotated for best viewing angle, usually looking toward the stand from the lowest side. All height measurements are in feet, as this was the value measured in the source .las files. Histograms and color displays are standardized to represent height above ground surface, although side view images reveal ground elevation and absolute elevations of tree crowns. 


\section{PCA Analysis of LiDAR Metrics}

Many of the LiDAR metrics were highly correlated with each other and normally distributed, indicating that principal component analysis (PCA) is an appropriate technique for reducing the dimension of variables (Figure 18). Height percentile metrics were highly correlated, particularly 90th and 95th percentile height (Pearson correlation $=$ 0.98), but did not show strong correlation with mean height. Canopy cover did not show a strong correlation with any other metrics. Rumple and Standard deviation of height, which relate to canopy structure, were highly correlated (Pearson correlation $=0.85$ ). They were also highly correlated to coefficient of variation of height, another measure related to structural heterogeneity.

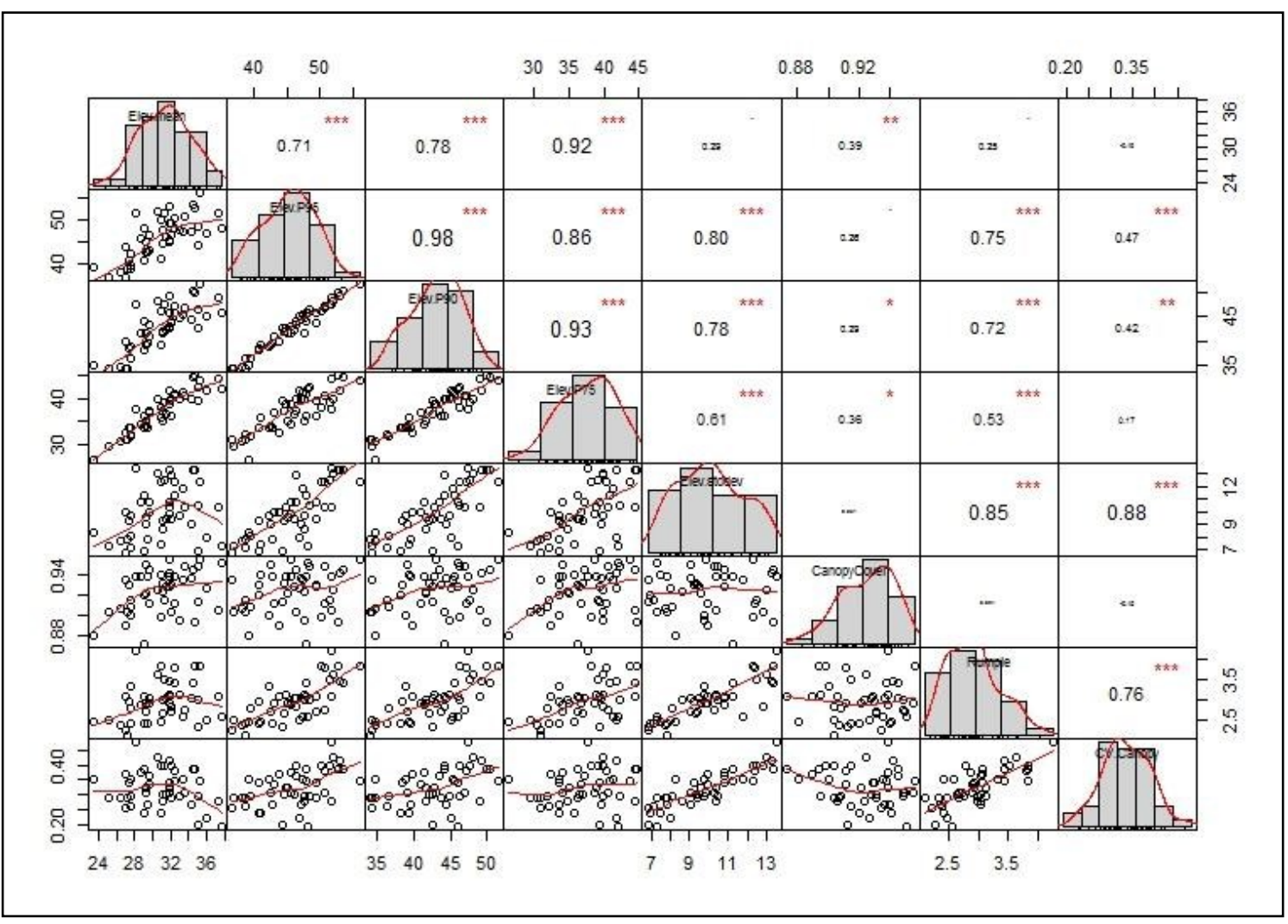

Figure 18: Pearson correlation rank of all 8 LiDAR metrics used in this analysis. Many metrics had a strong positive correlation with the other variables. 
After standardization, each variable showed a roughly normal distribution. PCA analysis yielded a total of 8 Components (Table 5), and component 1 and component 2 accounted collectively for $86.9 \%$ of the variation in the dataset $(62.3 \%$ and $24.6 \%$, respectively). These first two components utilized all of the metrics to a small degree, with PC2 being loaded most heavily by the 95th percentile height. Structural features such as canopy cover and canopy rumple were loaded most heavily on PC3, which only accounted for $9.2 \%$ of the variation.

Table 5: Loading of each variable within each component. Component 1 had a high degree of loading from each variable, with no particular variable dominating the loading. Comp 2 was most highly influenced by 95th percentile elevation, a measure of height and age of the oldest trees in the plot.

\begin{tabular}{|l|l|l|}
\hline Loadings: & Comp.1 & Comp.2 \\
\hline Elev.mean & -0.306 & 0.486 \\
\hline Elev.P95 & $\mathbf{- 0 . 4 3 4}$ & $\mathbf{0 . 7 3 8}$ \\
\hline Elev.P90 & -0.439 & 0.106 \\
\hline Elev.P75 & -0.398 & 0.282 \\
\hline Elev.stddev & -0.392 & -0.312 \\
\hline CanopyCover & -0.123 & 0.402 \\
\hline Rumple & -0.367 & -0.308 \\
\hline CV.Canopy & -0.252 & -0.563 \\
\hline
\end{tabular}

The bi-plot of the ordination showed a scattered distribution. Neither component could sufficiently distinguish between plots based on location, as the variability along the axes 
for urban, rural, and middle sites showed a high degree of overlap (Figure 19). Old Growth sites were clustered on the left side of PC1, reflecting most strongly the influence of tall, older trees. Plots that were clustered toward the right of PC1 (generally rural plots) had smaller canopy trees. Plots that are higher on the PC 2 (y-axis) have generally more canopy cover, and less canopy rumple, reflecting a smaller degree of canopy structure. Urban plots had the greatest amount of variation on the y-axis, reflecting slightly less canopy structure than other locations.

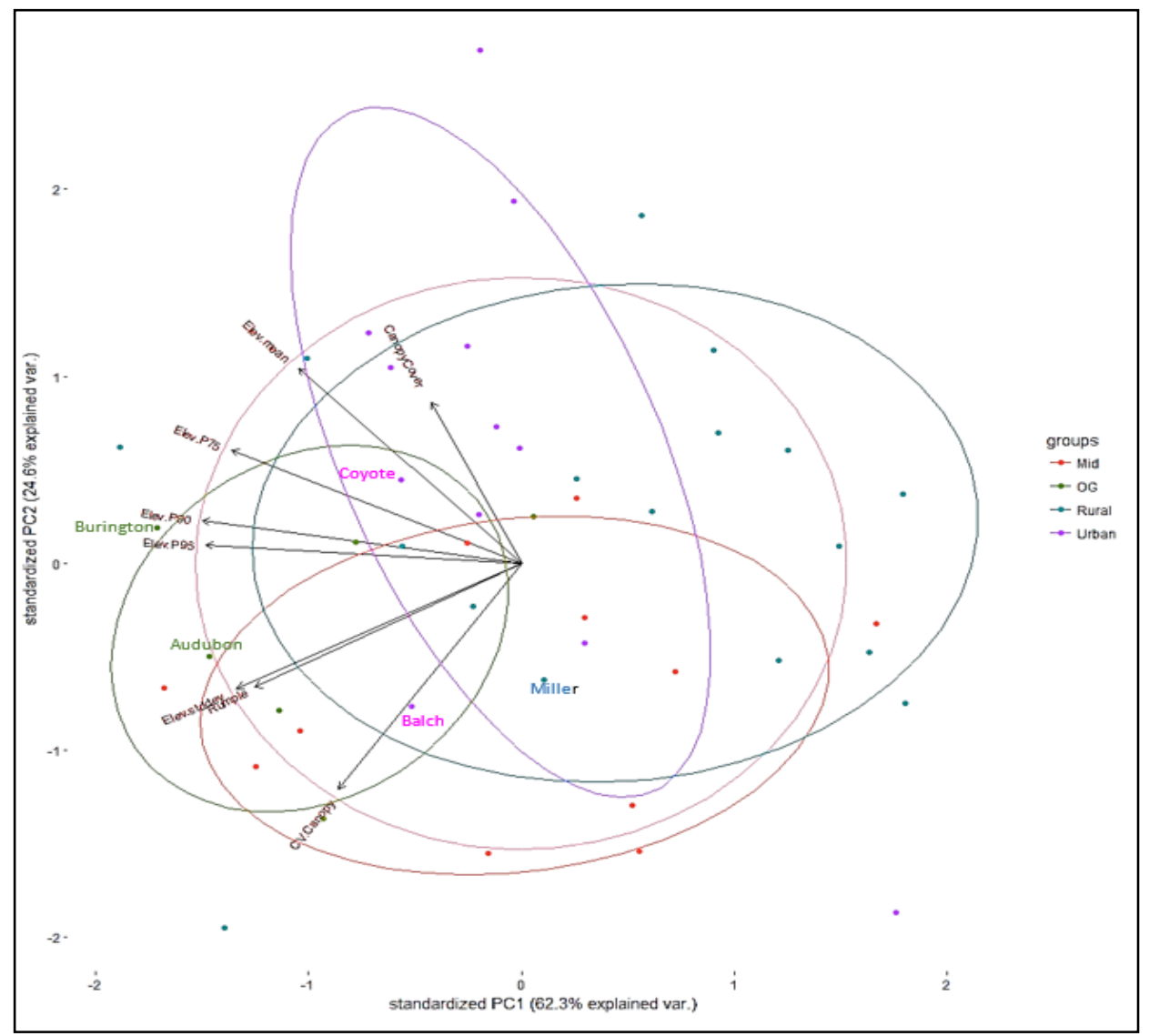

Figure 19: Bi-Plot of Principle Component Analysis Ordination of 8 LiDAR metrics for all 46 sampled plots. Length and direction of each arrow is proportional to the weight of that variable on the component axis. Individual plots are represented by colored dot. Ovals represent variability of each plot group along both axes, and plots that are closer together have more overall canopy characteristics in common. Generally, this plot shows that plots clustered on the left have taller trees than plots clustered toward the left, which have generally smaller canopy trees. 


\section{Discussion:}

\section{Productivity/Mortality}

In this study, we found that forest stand biomass ranged from approximately 500-700 $\mathrm{Mg} / \mathrm{ha}$ in our plots. Stands showed an age-related trend of greater biomass with increasing stand age. Older stands, such as the "old growth" plots, had more biomass than stands with fewer very large Douglas-fir trees. The biomass values found are within expected ranges and patterns found in other research of Douglas-fir-hemlock forests of the coastal PNW (Acker et al., 2002 Smithwick et al.,2002. Janisch and Harmon 2002).

Canopy trees in the older plots (Burlington and Audubon) had modest growth rates compared to Balch, our urban mature plot, which was likely related to competition. There were many more very tall trees in the old growth plots, which shade and compete with other large Douglas-fir used in this analysis. In the case of Balch, there were fewer trees overall, with more homogeneity in the size of canopy Douglas-fir trees, and consequently less shading of other large Douglas-fir. However, the large difference in growth rate deserves further study. It is possible that some urban impacts, such as increased $\mathrm{CO} 2$ and increases in temperature due to the urban heat island are creating more favorable conditions for tree growth for mature Douglas-fir trees (Ziska et al., 2004 O’Brien et al. (2012), found higher growth rate of Western Red Cedar in urban forests compared to rural forests in Seattle. Gregg et al., (2003) determined that tree growth was higher in an urban treatment, and suspected the cause was due to higher ozone concentrations inland of the city, using container grown cotton wood trees placed in an 
urban-rural gradient in New York. More study of tree growth along an urban-rural gradient in Forest Park and other urban forests could shed light on this potential effect.

Overall, the higher importance of density-independent mortality (such as treefall via wind/ice) compared to density-dependent causes (such as suppression) suggests these forest are displaying mortality patterns consistent with a natural pattern for mature stands of their age (Franklin et al., 2002). However, the lack of CWD in the urban mature plot contradicts predictions based on studies of other managed forests. Regenerating forests following clear-cut generally undergo a stem exclusion stage, with a high mortality rate before reaching a mature stage (Franklin et al., 2002). Due to this, stands generally have a very high tree density early in stand development, and lose density throughout maturation. In the process, the CWD store is replenished. However, the urban plot that had been clear-cut over 100 years ago, Balch, has the lowest tree density and CWD of all sites (Table 1; Figure 3). While Broshot (2011) found that tree mortality has been increasing throughout Forest Park in recent decades, with this impact most affecting urban stands, this research plot had a much lower overall rate of mortality for conifers in Balch, possibly due to its generally lower stand density.

\section{Soil}

Our study indicates that there may be a minor legacy of soil impact to urban stands most impacted by past intensive logging. The urban mature plot had higher mean soil $\mathrm{pH}$ (5.87, se: \pm 0.06$)$ compared to a rural mature plot and old growth reference plots located within the park. Mean coarse woody debris was lower at Balch (12.9 Mg/ha, se: \pm 1.64$)$ compared to the rural and old growth sites. O layer depth was thinner at Balch, but soil 
organic matter was not significantly different across sites suggesting that mineral soil organic matter is not highly sensitive to long-term depletion from past land use.

These results may provide a link between diminished soil quality and the lack of shade-tolerant seedling recruitment found in Balch. For instance, soil $\mathrm{pH}$ was found to be significantly higher in Balch (mean $\mathrm{pH}$ 5.9) relative to the other sites (mean $\mathrm{pH}$ ranges closer to 5.0 for the three other plots). Goble silt loam soils are uniquely found in northwest Oregon and reported $\mathrm{pH}$ values typically range from 5.4 - 5.6 (Soil Survey Staff, NRCS) but Old-growth hemlock forests in the Oregon Cascades can have pH values closer to 4.9 (Griffiths et al., 2009). Disturbances due to logging or fire (Hornbeck, 1992; Certini, 2005) can raise soil $\mathrm{pH}$ in the short term, but there is no known report of irreversible long-term changes to soil $\mathrm{pH}$ due to logging.

Changes to soil $\mathrm{pH}$ can shift the concentration of available forms of limiting nutrients (such as nitrogen) in ways that have differential impacts on late-successional tree species (Kronzucker et al., 1997) Late-successional conifers may be adapted to low $\mathrm{pH}$ soils through a preference for ammonium which is the predominate form of nitrogen in acidic soils (Vogt and Edmonds, 1982). Krajina et al. (1973) showed that western hemlock growth rate is enhanced when there is a mix of available nitrate and ammonium, as opposed to ammonium or nitrate alone. Given the less acidic $\mathrm{pH}$ in the soil of Balch revealed in this study, future research could look at the nitrogen cycle dynamics between Forest Park sites to determine whether there are differences in relative concentrations of ammonium and nitrate. A lack of ammonium could be related to the generally suppressed recruitment of shade tolerant species in the urban mature sites (Krajina et al., 1973). 


\section{Soil Organic Matter}

Soil OM did not vary significantly between sites. This was unexpected given the evidence of soil damage in the urban site by past land use, it's steep topography, and the relatively shallow surface soil horizons. However, it is generally consistent with a large body of forestry research related to the long-term impacts of forest management on site productivity and soil carbon. Soil OM is sensitive to harvesting, but the mineral soil layer is generally less sensitive than the forest floor and surface organic layers (Nave et al., 2010; James and Harrison, 2016). An overlooked explanation for the observed loss of forest floor organic material found in most studies could be the mixing of surface horizons with deeper mineral horizons during harvest, and thus OM may actually increase in deeper soil layers following harvest (Yanai et al. 2003). Long-term studies of soil changes due to harvest have largely determined that forest floor and soil carbon losses recover within a few decades of disturbance (Covington, 1981; Johnson et al., 2002). Thus, mineral soil layers may not be sensitive to logging related soil impacts at a time scale that is relevant for the mature forest stands found in Forest Park

\section{$\operatorname{LiDAR}$}

LiDAR analysis revealed some variation in canopy structure along an urban-rural gradient that can inform our understanding of forest dynamics in Forest Park. Older plots that tend to have larger and taller trees could be distinguished from slightly younger plots using height metrics. Old-growth plots predictably had higher percentile height values than all other plots. Rural plots tended to have slightly smaller trees, as determined by 
height metrics, than all other groups. This confirms observations by McDonald (2011) who estimated stand age using tree cores, determining the largest canopy trees in Miller Plot were generally 5-10 years younger than those in the urban plots.

Measures of canopy structure were also highest in the old-growth stands, but were lowest in the rural plots. This is surprising, given that species and age diversity are higher in Miller plot, and recent patterns of mortality would suggest large canopy gaps are forming. These gap forming processes should develop some detectable level of canopy structure. However, Miller did not differ substantially from urban mature plots in the degree of canopy rumple. Further, Miller was generally higher than other sampled rural plots in both height and measures of canopy structure. It may be that Miller is slightly more advanced in the development of structure and diversity compared to other stands in the rural section of the park.

Differences in stand age and canopy complexity likely reflects the differing periods and styles of logging across the park. Middle sections of the park appear to have a high degree of canopy structural variability and also have generally tall trees. While large sections of middle park are deciduous dominant due to large stand replacing fires in the 1950's (Kuhn, 2005), sections that did not burn severely may have retained a large number of conifer trees which today form an overall taller and more heterogeneous stand than other rural sections of the park. Broshot (2007) found "Middle" stands had few shade-tolerant conifers and were generally dominated by big-leaf maple. However her transect may not have adequately sampled portions of the middle park with conifer dominant stands. It would be informative to perform more in-depth ground level surveys 
of conifer dominant stands in the middle sections of Forest Park to see how successional patterns might be related, or differ, from urban and rural sections.

The entire Balch watershed that contains the urban plots was clear-cut at least once by 1900, and wood-cutting camps were established in the 1920's to salvage any remaining stands and downed wood (Munger, 1960). Logging in the more rural end of the park seems to have involved high-grade logging used for industrial purposes (Scheller, Personal communication). Due to the less intensive logging practices in the rural section of the park, wide scale slash burning was probably not a major impact to most rural stands. Further, the major fires of 1889, 1940, and 1951 were more concentrated in the middle and urban sections of the park than the northernmost extents (Kuhn, 2005.) This has implications for tree species composition. Because fire impacts and logging practices differed across sections of the park, smaller late-successional conifers saplings were retained in more rural plots. These trees now contribute seed as mature adults (Table 6).

This analysis shows that LiDAR could be a useful and comlimentary tool for assessing forest structure in an urban forest. There have been relatively few studies of LiDAR as a tool to study urban forests along an urban-rural gradient, however. LiDAR has been used to quantify carbon stocks in urban street trees (Singh et al., 2015), although Mchale et al., (2009) found large variation of predicted and actual street tree mass when predicted by allometric equations developed for more densely forested areas. Voss and Sugumaran (2007) were able to distinguish between 7 classes of street trees in Cedar Falls, Iowa. 
Table 6: The abundance of shade-tolerant conifer species in 4 plots in forest. This table highlights the relationship of large seed trees $(>30 \mathrm{~cm} \mathbf{d b h})$ to the overall abundance of saplings. It also suggests that the lack of remnant shade-tolerant conifers in Balch from a history of more intense logging and fire could be driving the dearth of young saplings. THPL- Thuja plicata, western red cedar. TSHE- Tsuga heterophylla, western hemlock.

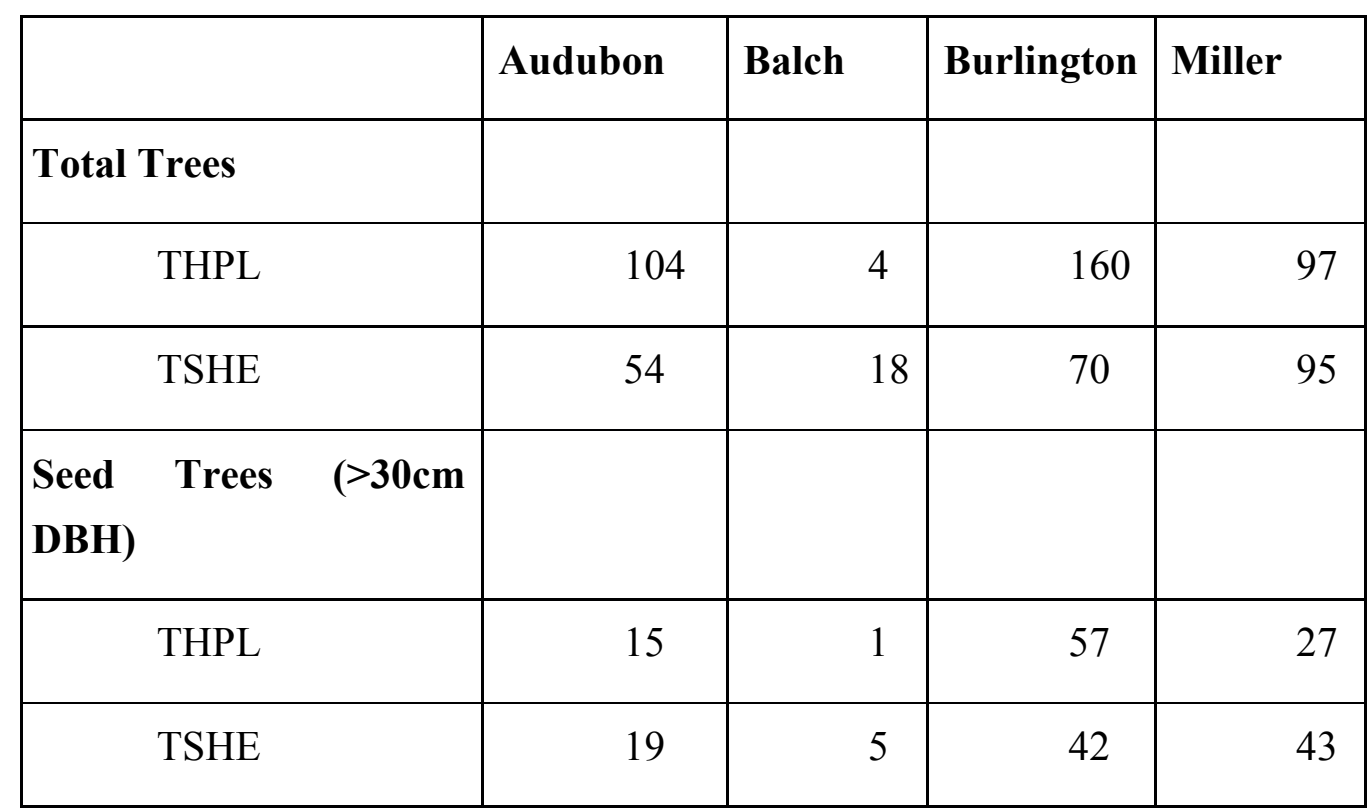

This analysis shows that LiDAR could be a useful and comlimentary tool for assessing forest structure in an urban forest. There have been relatively few studies of LiDAR as a tool to study urban forests along an urban-rural gradient, however. LiDAR has been used to quantify carbon stocks in urban street trees (Singh et al., 2015), although Mchale et al., (2009) found large variation of predicted and actual street tree mass when predicted by allometric equations developed for more densely forested areas. Voss and Sugumaran (2007) were able to distinguish between 7 classes of street trees in Cedar Falls, Iowa.

One potential application of LiDAR in urban forests would be to compare acquisitions taken at different time points to assess productivity over a large area. Yu et 
al., (2006) compared 5-year plot level differences of Boreal conifer forests Finland using a variety of LiDAR derived metrics, and Naesset \& Gobakken (2005) accurately detected growth in only a 2-year interval. I attempted to compare LiDAR acquisitions taken in 2003 with the 2014 LiDAR data used in this study, however, source LiDAR (.las) files were not available and only raster surfaces could be found for the 2003 data. Further, the timing, point density, and laser technology differences between the two datasets differed to such a degree that direct comparison was not achievable.

Urban-rural gradient studies using LiDAR could help yield more information on how tree growth and forest structure is impacted by urban air pollution, urban heat islands, and edge effects. LiDAR may become a more common tool used to assess urban forest stocks and structure, as many city and regional governments have already acquired LiDAR data for their metropolitan regions to assist with planning and urban feature modeling, and this data can be shared with researchers without cost. Paired with groundlevel plot data from Long-term research sites, LiDAR could help provide a broad, complementary understanding of how forests near dense human settlement are affected by past land-use and urban impacts. 


\section{Conclusions}

Collectively, work in PSU's long-term ecological research plots in Forest Park has begun to reveal an understanding of forest dynamics in this large urban forest. Future studies should build on this work to further clarify how natural age-related developmental processes, legacies of past land use, and ongoing urban impacts are involved in driving stand structure in the park. Assessing how the forest may be responding to urban air pollution and other aspects of urbanization should be a priority for future research.

Our research highlights different patterns driving the development of latesuccessional features across stands. Gap-forming mortality from density-independent causes, such as wind disturbance, has provided a dense layer of large CWD in rural and "old-growth" stands. In the urban plots, however, there were low amounts of initial CWD and a lack of input over the last 5 years. Neither the lack of CWD, nor the evidence of more intensive past logging absent in the urban sections of the park had a clear effect on the upper mineral soil organic matter content, however. Future studies could look at litter layer depth, or compare fungal and microbial communities across research plots. We did find, however, elevated soil $\mathrm{pH}$ in the urban plot, along with clear signs of soil impacts evident in "slumps" from mass erosion and remnant logging trails. Assessing changes to biogeochemical cycles, particularly the relative amounts of different forms of nitrogen (i.e., ammonium and nitrate) could yield further understanding of how forest soils are affected by urbanization and land-use history.

Lastly, we found that LiDAR data extracted from acquisitions covering metropolitan regions could provide a valuable tool to assess canopy structure and 
productivity along an urban-rural gradient. There was a high degree of overlap in canopy height and structural measures across Forest Park, which is to be expected in stands of similar age. However, we did see some divergence in the development of canopy structural features that is detectable using LiDAR data. Monitoring of canopy structure and stand level productivity along an urban-rural gradient could be a rich area of exploration in follow-up work.

One legacy of past land-use that seems to be a major factor in diverging successional patterns in Forest Park is the lack of large shade-tolerant conifer seed trees in the urban park, which corresponds to a lack of seedlings for these species of trees. This may be caused by past logging practices. Intensive clear-cuts appear to have been concentrated in the urban section of the park. Logging practices that involve removal of all trees, and the follow-up treatment of broadcast burning, can remove seed trees of late successional tree and plant species that otherwise might survive a natural stand clearing disturbance. In contrast, natural stand replacing disturbances such as fire can retain at least some mature late-successional trees that provide seed for the regenerating stand as fire-susceptible shade-tolerant conifers can often survive in convergent topographies, such as in riparian areas (Keeton, 2005). Surviving legacy trees are an important seed source for shade-tolerant conifers (Poage, 1994; Schrader, 1998) and increase the rate of late-successional forest development in a maturing stand (Keeton, 2005; Keeton and Franklin, 2005). A lack of seed source for shade-tolerant trees could inevitably delay the development of maturing Douglas-fir forests (Gray \& Spies, 1996). 
The lack of CWD in urban plots compounds this relative lack of seed source in the urban mature plots. Large CWD is essential for the germination and growth of young shade tolerant conifers like western hemlock and western red cedar. Although decomposing downed logs are generally a poorer source of nutrition for developing plants than soil, the seedlings of many late-successional tree species (particularly western hemlock) depends on CWD for germination (Christy \& Mack, 1984; Harmon and Franklin, 1989). CWD protects seedlings from competition with ground cover or shrub species, as well as from trampling, heavy snowpack, or grazing. Without the buffering protection of CWD, it is unlikely that the relatively small seed bank from the few remnant adult shade-tolerant conifers can produce viable seedlings to regenerate in the forest sub-canopy.

Another notable urban impact that was not a focus of this study is the role of nonnative species invasions, particularly English ivy. English ivy (Hedera spp.) is an invasive species of liana (climbing vine) introduced to Pacific Northwest forests. Ivy can grow abundantly on forest floors, and also climb up the trunk of host trees, rock walls, and other vertical substrate by adhesion of stem hairs to vertical surfaces (Melzer et al., 2010). Ivy reduces biodiversity by outcompeting native ground cover and shrub species (Okerman, 2000; Quinn \& Best, 2002; Dlugosch, 2005; Copp, 2014). Ivy invasion has been concentrated in urban sections of the park that also show reduced late-successional conifer recruitment, and controlling the spread of ivy has become a primary objective for park-managers as well as community volunteers. However, it is unclear if ivy is driving reduced tree establishment, or if the spread of ivy is simply the result of the same factors 
that negatively influence late-successional conifer establishment, such as soil disturbance, pH changes, or edge effects (Schnitzer \& Bongers, 2002; Leicht-Young et al., 2010; Pavlovic \& Leicht-Young, 2011.)

\section{Management Implications}

Overall, these results help inform environmental managers that the lack of regenerating late successional tree species in mature urban conifer forests may limit the long-term development of old-growth structure. In Forest Park, active restoration practices that focus on planting and monitoring saplings of late successional tree species in mature forests where they are lacking should become a priority. Successful recruitment of western hemlock and western red cedar may also require input of CWD through thinning large Douglas-fir to provide microsites for germination of western hemlock and western red cedar seed. In some cases, addition of CWD may be more important than removal of invasive ivy for the successful regeneration of late-successional species. This was the conclusion reached in a notable recent study in urban parks in Seattle, where limited late-successional conifer recruitment was also an issue. Addition of CWD had a more positive effect on seed germination than removal of ivy (Ettinger et al., 2017).

There is widespread recognition that managing forest landscapes for structural diversity that lead to old-growth characteristics is an important objective. At the same time, it is becoming increasingly clear that anthropogenic impacts are negatively affecting the vast majority of ecosystems on Earth. Land use-legacies, global climate change, and impacts of urbanization are increasingly altering natural patterns of ecosystem development and leading to novel systems around the world (Radeloff et al., 
2015). There have been cases where aggressive land-conversion practices have completely extirpated late successional tree species over very large areas. This process has been documented in the Upper Midwestern US, where eastern hemlock (Tsuga canadensis) forests have been completely lost from the landscape due to past logging and agriculture (White and Mladenoff, 1994; Goring et al., 2015).

Understanding ecosystems in urbanizing regions through the use of long-term ecological study and the integration of social and ecological sciences is essential to documenting and counteracting the detrimental impacts of human driven ecosystem changes. In Forest Park, our ecological research revealed important mechanisms for how urbanization and past land-use may be driving alterations to forest composition. Given the importance of Forest Park in connecting the Coast Range Biome to the Portland metro area and Willamette Valley, restoring and maintaining suitable late-successional forest habitat should remain an important objective for forest managers. 


\section{References}

Acker, S. A., Halpern, C. B., Harmon, M. E., \& Dyrness, C. T. (2002). Trends in bole biomass accumulation, net primary production and tree mortality in Pseudotsuga menziesii forests of contrasting age. Tree Physiology, 22(2), 213-217.

Alvey, A. A. (2006). Promoting and preserving biodiversity in the urban forest. Urban Forestry \& Urban Greening, 5(4), 195-201.

Britto, D. T., and Kronzucker, H. J. (2002). NH4+ toxicity in higher plants: a critical review. Journal of Plant Physiology, 159(6), 567-584.

Broshot, N. E. (2007). The influence of urbanization on forest stand dynamics in Northwestern Oregon. Urban Ecosystems, 10(3), 285-298. https://doi.org/10.1007/s11252-007-0023-x

Broshot, N. E. (2011). Mortality and recruitment in an urban forest (Forest Park in Portland, Oregon) between 1993 and 2003. Urban Ecosystems, 14(4), 553-567.

Brown, J.K. (1974). Handbook for inventorying downed woody material. GTR-INT-16. USDA

Carreiro, M. M., and Tripler C.E. (2005) Forest remnants along urban-rural gradients: examining their potential for global change research. Ecosystems 8(5), 568-582.

Certini, G. (2005). Effects of fire on properties of forest soils: a review. Oecologia, 143(1), 1-10.

Christy, E., and Mack, R. (1984). Variation in Demography of Juvenile Tsuga Heterophylla Across the Substratum Mosaic. Journal of Ecology, 72(1), 75-91. doi: $10.2307 / 2260007$

Copp, S. R. (2014). Community level impacts associated with the invasion of English ivy (Hedera spp.) in Forest Park: a look at the impacts of ivy on community composition and soil moisture. PDXscholar Dissertations and theses. Paper 2024. 
Covington, W. W. (1981). Changes in forest floor organic matter and nutrient content following clear cutting in northern hardwoods. Ecology, 62(1), 41-48.

DeVoto B (ed) (1953) The journals of Lewis and Clark. Houghton Mifflin, Boston, MA, p 504

Dixon, R., Brown, S., Houghton, R. E. A., Solomon, A. M., Trexler, M. C., \& Wisniewski, J. (1994). Carbon pools and flux of global forest ecosystems. Science(Washington), 263(5144), 185-189.

Dlugosch, K. M. (2005). Understory community changes associated with English ivy invasions in Seattle's urban parks. Northwest science, 79(1).

Dresner, M. (in review). Urban forest disturbance history influences native tree composition, abundance, and structure, altering expected succession pattern. Unpublished research.

Dupouey, J. L., Dambrine, E., Laffite, J. D., \& Moares, C. (2002). Irreversible impact of past land use on forest soils and biodiversity. Ecology, 83(11), 2978-2984.

Ettinger, A. K., Lee, B. R., \& Montgomery, S. (2017). Seed limitation and lack of downed wood, not invasive species, threaten conifer regeneration in an urban forest. Urban Ecosystems, 1-11.

Federer, C. A. (1984). Organic matter and nitrogen content of the forest floor in evenaged northern hardwoods. Canadian Journal of Forest Research, 14(6), 763-767.

Forest Park Conservancy and Forest Park Alliance. 2013. Greater Forest Park Conservation

Foster, D. R., Aber, J. D., Melillo, J. M., Bowden, R. D., \& Bazzaz, F. A. (1997). Forest response to disturbance and anthropogenic stress. BioScience, 47(7), 437-445.

Foster, D., Swanson, F., Aber, J., Burke, I., Brokaw, N., Tilman, D., \& Knapp, A. (2003). The importance of land-use legacies to ecology and conservation. BioScience. 53(1), 7788 . 
Franklin, J. F., Spies, T. A., Van Pelt, R., Carey, A. B., Thornburgh, D. A., Berg, D. R., ... \& Bible, K. (2002). Disturbances and structural development of natural forest ecosystems with silvicultural implications, using Douglas-fir forests as an example. Forest Ecology and Management, 155(1), 399-423.

Franklin, Jerry F.; Cromack, Kermit Jr.; Denison, William; McKee, Arthur; Maser, Chris; Sedell, James; Swanson, Fred; Juday, Glen. 1981. Ecological characteristics of oldgrowth Douglas-fir forests. Gen. Tech. Rep. PNW-GTR-118. Portland, OR: U.S. Department of Agriculture, Forest Service, Pacific Northwest Research Station. 48 p

Gatziolis, Demetrios; Andersen, Hans-Erik. 2008. A guide to LIDAR data acquisition and processing for the forests of the Pacific Northwest. Gen. Tech. Rep. PNW-GTR-768. Portland, OR: U.S. Department of Agriculture, Forest Service, Pacific Northwest Research Station. 32 p.

Goring, S., Mladenoff, D. J., Cogbill, C. V., Record, S., Paciorek, C. J., Jackson, S. T., ... \& Williams, J. W. (2015). Changes in forest composition, stem density, and biomass from the settlement era (1800s) to present in the upper midwestern United States. bioRxiv, 026575 .

Gray, A. N., \& Spies, T. A. (1996). Gap size, within-gap position and canopy structure effects on conifer seedling establishment. Journal of ecology, 635-645.

Gray, A. N., Whittier, T. R., \& Harmon, M. E. (2016). Carbon stocks and accumulation rates in Pacific Northwest forests: role of stand age, plant community, and productivity. Ecosphere, 7(1).

Gregg, J. W., Jones, C. G., \& Dawson, T. E. (2003). Urbanization effects on tree growth in the vicinity of New York City. Nature, 424(6945), 183-187.

Griffiths, R. P., Madritch, M. D., \& Swanson, A. K. (2009). The effects of topography on forest soil characteristics in the Oregon Cascade Mountains (USA): Implications for the effects of climate change on soil properties. Forest Ecology and Management, 257(1), 17.

Grigal, D. F. (2000). Effects of extensive forest management on soil productivity. Forest Ecology and Management, 138(1), 167-185. 
Grimm, N. B., Morgan Grove, J., Pickett, S. T., \& Redman, C. L. (2000). Integrated Approaches to Long-TermStudies of Urban Ecological Systems: Urban ecological systems present multiple challenges to ecologists - pervasive human impact and extreme heterogeneity of cities, and the need to integrate social and ecological approaches, concepts, and theory. BioScience, 50(7), 571-584.

Groffman, P. M., Pouyat, R. V., Cadenasso, M. L., Zipperer, W. C., Szlavecz, K., Yesilonis, I. D., \& Brush, G. S. (2006). Land use context and natural soil controls on plant community composition and soil nitrogen and carbon dynamics in urban and rural forests. Forest Ecology and Management, 236(2), 177-192.

Hagan, J. M., \& Grove, S. L. (1999). Coarse woody debris: humans and nature competing for trees. Journal of Forestry, 97(1), 6-11.

Hansen, A. J., Spies, T. A., Swanson, F. J., \& Ohmann, J. L. (1991). Conserving biodiversity in managed forests. BioScience, 41(6), 382-392.

Harmon, M. E., Franklin, J. F., Swanson, F. J., Sollins, P., Gregory, S. V., Lattin, J. D., ... \& Lienkaemper, G. W. (1986). Ecology of coarse woody debris in temperate ecosystems. Advances in ecological research, 15, 133-302.

Hornbeck, J. W. (1992). Comparative impacts of forest harvest and acid precipitation on soil and streamwater acidity. Environmental Pollution, 77(2-3), 151-155.

Houle, M.C. (1996). One City's Wilderness, 2nd Edition. Portland, OR: The Oregon Historical Society

Houle, M.C. (2010). One City's Wilderness: Portland's Forest Park (3rd ed.). Corvallis: Oregon State University Press. ISBN 978-0-87071-588-4

Ishii, H. T., Tanabe, S. I., \& Hiura, T. (2004). Exploring the relationships among canopy structure, stand productivity, and biodiversity of temperate forest ecosystems. Forest Science, 50(3), 342-355.

James, J., \& Harrison, R. (2016). The Effect of Harvest on Forest Soil Carbon: A MetaAnalysis. Forests, 7(12), 308. 
Janisch, J. E., \& Harmon, M. E. (2002). Successional changes in live and dead wood carbon stores: implications for net ecosystem productivity. Tree Physiology, 22(2), 7789.

Jenkins, J. C., Chojnacky, D. C., Heath, L. S., \& Birdsey, R. A. (2004). Comprehensive database of diameter-based biomass regressions for North American tree species.

Johnson, D. W., Knoepp, J. D., Swank, W. T., Shan, J., Morris, L. A., Van Lear, D. H., \& Kapeluck, P. R. (2002). Effects of forest management on soil carbon: results of some long-term resampling studies. Environmental Pollution, 116, S201-S208.

Kalra, Y. P., \& Maynard, D. G. (1991). Methods manual for forest soil and plant analysis. For. Can., Northwest Reg., North. For. Cent., Edmonton, Alberta. Inf. Rep. NOR-X-319.

Kane, V. R., Bakker, J. D., McGaughey, R. J., Lutz, J. A., Gersonde, R. F., \& Franklin, J. F. (2010a). Examining conifer canopy structural complexity across forest ages and elevations with LiDAR data. Canadian Journal of Forest Research, 40(4), 774-787.

Kane, V. R., McGaughey, R. J., Bakker, J. D., Gersonde, R. F., Lutz, J. A., \& Franklin, J. F. (2010b). Comparisons between field-and LiDAR-based measures of stand structural complexity. Canadian Journal of Forest Research, 40(4), 761-773.

Keeton, W. S., \& Franklin, J. F. (2005). Do remnant old- growth trees accelerate rates of succession in mature Douglas- fir forests?. Ecological Monographs, 75(1), 103-118.

Keeton, W. S., \& Franklin, J. F. (2005). Do remnant old- growth trees accelerate rates of succession in mature Douglas- fir forests?. Ecological Monographs, 75(1), 103-118.

Krajina, V. J., Madoc-Jones, S., \& Mellor, G. (1973). Ammonium and nitrate in the nitrogen economy of some conifers growing in Douglas-fir communities of the Pacific North-West of America. Soil Biology and Biochemistry, 5(1), 143-147.

Kronzucker, H. J., Siddiqi, M. Y., \& Glass, A. D. (1997). Conifer root discrimination against soil nitrate and the ecology of forest succession. Nature, 385(6611), 59. 
Kuhn, D. (2005). Fire in Forest Park. (Unpublished Masters Thesis). Portland State University, Portland, Oregon.

Lefsky, M. A., Cohen, W. B., Parker, G. G., \& Harding, D. J. (2002). Lidar remote sensing for ecosystem studies: Lidar, an emerging remote sensing technology that directly measures the three-dimensional distribution of plant canopies, can accurately estimate vegetation structural attributes and should be of particular interest to forest, landscape, and global ecologists. BioScience, 52(1), 19-30.

Leicht-Young, S. A., Pavlovic, N. B., Frohnapple, K. J., \& Grundel, R. (2010). Liana habitat and host preferences in northern temperate forests. Forest Ecology and Management, 260(9), 1467-1477.

Loeb, R. E. (2011). What and Where Are Old Growth Urban Forests?. In Old growth urban forests (pp. 1-14). Springer New York.

McAllister, D., Dragoy, A., Moeller, D., Petersen-Morgan, K., Roth, E., Darling, J., Keyes, C. (2011). Forest Park desired future conditions. Portland Parks and Recreation, Portland, Oregon. $33 \mathrm{p}$.

McDonald, Hannah Beth. (2011). Tree Growth and Spatial Pattern in Two Forest Park Permanent Plots: A Look at Stand Composition and Condition. PDXscholar Dissertations and theses. Paper 313.

McGaughey, R. J., 2009,. FUSION/LDV: Software for LIDAR data analysis and visualization. US Department of Agriculture, Forest Service, Pacific Northwest Research Station: Seattle, WA, USA, 123(2).

McHale, M. R., Burke, I. C., Lefsky, M. A., Peper, P. J., \& McPherson, E. G. (2009). Urban forest biomass estimates: is it important to use allometric relationships developed specifically for urban trees?. Urban Ecosystems, 12(1), 95-113.

McKinley, D. C., Ryan, M. G., Birdsey, R. A., Giardina, C. P., Harmon, M. E., Heath, L. S., ... \& Pataki, D. E. (2011). A synthesis of current knowledge on forests and carbon storage in the United States. Ecological applications, 21(6), 1902-1924. 
McKinney, M. L. (2002). Urbanization, Biodiversity, and Conservation. Bioscience, 52(10), 883-890.

Medley, K. E., McDonnell, M. J., \& Pickett, S. T. (1995). Forest- Landscape Structure along an Urban- To- Rural Gradient. The Professional Geographer, 47(2), 159-168.

Melzer, B., Steinbrecher, T., Seidel, R., Kraft, O., Schwaiger, R., \& Speck, T. (2010). The attachment strategy of English ivy: a complex mechanism acting on several hierarchical levels. Journal of the Royal Society Interface, 7(50), 1383-1389.

Munger, T. T. (1960). History of Portland's Forest Park.

Næsset, E., \& Gobakken, T. (2005). Estimating forest growth using canopy metrics derived from airborne laser scanner data. Remote sensing of environment, 96(3), 453465.

Nave, L. E., Vance, E. D., Swanston, C. W., \& Curtis, P. S. (2010). Harvest impacts on soil carbon storage in temperate forests. Forest Ecology and Management, 259(5), 857866.

O'Brien, A. M., Ettinger, A. K., \& HilleRisLambers, J. (2012). Conifer growth and reproduction in urban forest fragments: Predictors of future responses to global change?. Urban Ecosystems, 15(4), 879-891.

Okerman, A. (2000). Combating the "ivy desert": the invasion of Hedera helix (English ivy) in the Pacific Northwest United States. Restoration and Reclamation Review, 6(4), $1-10$.

Patenaude, G., Hill, R. A., Milne, R., Gaveau, D. L., Briggs, B. B. J., \& Dawson, T. P. (2004). Quantifying forest above ground carbon content using LiDAR remote sensing. Remote Sensing of Environment, 93(3), 368-380.

Pavlovic, N. B., \& Leicht-Young, S. A. (2011). Are temperate mature forests buffered from invasive lianas? 1. The Journal of the Torrey Botanical Society, 138(1), 85-92. 
Pennock, D. J., and Van Kessel, C. (1997). Clear-cut forest harvest impacts on soil quality indicators in the mixedwood forest of Saskatchewan, Canada. Geoderma, 75(1-2), 13-32.

Poage, N. J. (1994). Comparison of stand development of a deciduous-dominated riparian forest and a coniferous-dominated riparian forest in the Oregon Coast Range (Doctoral dissertation).

Quinn, H., and Best, R. (2002). English ivy in Stanley Park: Effects of the invasion and implications for management. UBC Environmental Sciences Masters Thesis, 129.

Radeloff, V. C., Williams, J. W., Bateman, B. L., Burke, K. D., Carter, S. K., Childress, E. S., ... \& Latzka, A. W. (2015). The rise of novelty in ecosystems. Ecological Applications, 25(8), 2051-2068.

Rubin, R. (1999) Naked Against the Rain: The People of the Lower Columbia River 1770-1830. Far Shore Press.

Schnitzer, S. A., \& Bongers, F. (2002). The ecology of lianas and their role in forests. Trends in Ecology \& Evolution, 17(5), 223-230.

Schoenholtz, S. H., Miegroet, H. V., \& Burger, J. . (2000). A review of chemical and physical properties as indicators of forest soil quality: challenges and opportunities. Forest Ecology and Management, 138(1-3), 335-356. https://doi.org/10.1016/S03781127(00)00423-0

Schrader, B. A. (1998). Structural development of late successional forests in the central Oregon Coast Range: abundance, dispersal, and growth of western hemlock (Tsuga heterophylla) regeneration (Doctoral dissertation).

Schrader, B. A. (1998). Structural development of late successional forests in the central Oregon Coast Range: abundance, dispersal, and growth of western hemlock (Tsuga heterophylla) regeneration (Doctoral dissertation).

Seely, B., Welham, C., \& Blanco, J. A. (2010). Towards the application of soil organic matter as an indicator of forest ecosystem productivity: Deriving thresholds, developing monitoring systems, and evaluating practices. Ecological Indicators, 10(5), 999-1008. 
Singh, K. K., Chen, G., McCarter, J. B., \& Meentemeyer, R. K. (2015). Effects of LiDAR point density and landscape context on estimates of urban forest biomass. ISPRS Journal of Photogrammetry and Remote Sensing, 101, 310-322.

Smithwick, E. A., Harmon, M. E., Remillard, S. M., Acker, S. A., \& Franklin, J. F. (2002). Potential upper bounds of carbon stores in forests of the Pacific Northwest. Ecological Applications, 12(5), 1303-1317.

Soil Survey Staff, Natural Resources Conservation Service, United States Department of Agriculture. Web Soil Survey. Available online at https://websoilsurvey.sc.egov.usda.gov/. Accessed [3/3/2017].

Spies, T. A., \& Franklin, J. F. (1991). The structure of natural young, mature, and oldgrowth Douglas-fir forests in Oregon and Washington. Wildlife and vegetation of unmanaged Douglas-fir forests, 91-109.

Spies, T. A., and Franklin, J. F. (1991). The structure of natural young, mature, and oldgrowth Douglas-fir forests in Oregon and Washington. Wildlife and vegetation of unmanaged Douglas-fir forests, 91-109.

Spies, T. A., Franklin, J. F., \& Thomas, T. B. (1988). Coarse woody debris in Douglasfir forests of western Oregon and Washington. Ecology, 69(6), 1689-1702.

Sugumaran, R., \& Voss, M. (2007, April). Object-oriented classification of LIDAR-fused hyperspectral imagery for tree species identification in an urban environment. In Urban Remote Sensing Joint Event, 2007 (pp. 1-6). IEEE.

Van Mantgem, P. J., Stephenson, N. L., Byrne, J. C., Daniels, L. D., Franklin, J. F., Fulé, P. Z., ... \& Veblen, T. T. (2009). Widespread increase of tree mortality rates in the western United States. Science, 323(5913), 521-524.

Van Pelt, R., \& Nadkarni, N. M. (2004). Development of canopy structure in Pseudotsuga menziesii forests in the southern Washington Cascades. Forest Science, 50(3), 326-341. 
Van Winkle, J. E. (2014). Informal Trails and the Spread of Invasive Species in Urban Natural Areas: Spatial Analysis of Informal Trails and their Effects on Understory Plant Communities in Forest Park, Portland, Oregon. Portland State University, Portland, Oregon.

Vogt, D. J., \& Edmonds, R. L. (1982). Nitrate and ammonium levels in relation to site quality in Douglas-fir soil and litter. Northwest Science, 56(2), 83-89.

White, M. A., \& Mladenoff, D. J. (1994). Old-growth forest landscape transitions from pre-European settlement to present. Landscape Ecology, 9(3), 191-205.

WSI (2014) OLC Metro 2014: Final Delivery (pp. 1-18, Tech.). Portland, OR: WSI, A Quantum Spatial Company. Portland State server location for source LiDAR data, I: $\backslash$ Research $\backslash$ Shares \lidar

Wulder, M. A., Bater, C. W., Coops, N. C., Hilker, T., \& White, J. C. (2008). The role of LiDAR in sustainable forest management. The Forestry Chronicle, 84(6), 807-826.

Wulder, M. A., White, J. C., Nelson, R. F., Næsset, E., Ørka, H. O., Coops, N. C., ... \& Gobakken, T. (2012). Lidar sampling for large-area forest characterization: A review. Remote Sensing of Environment, 121, 196-209.

Yanai, R. D., Currie, W. S., \& Goodale, C. L. (2003). Soil carbon dynamics after forest harvest: an ecosystem paradigm reconsidered. Ecosystems, 6(3), 197-212.

Yu, X., Hyyppä, J., Kukko, A., Maltamo, M., \& Kaartinen, H. (2006). Change detection techniques for canopy height growth measurements using airborne laser scanner data. Photogrammetric Engineering \& Remote Sensing, 72(12), 1339-1348.

Zipperer, W. C., and Guntenspergen, G. R. (2009). Vegetation composition and structure of forest patches along urban-rural gradients. Ecology of cities and towns: a comparative approach. Cambridge University Press, New York, 274-286.

Ziska, L. H., Bunce, J. A., \& Goins, E. W. (2004). Characterization of an urban-rural $\mathrm{CO} 2 /$ temperature gradient and associated changes in initial plant productivity during secondary succession. Oecologia, 139(3), 454-458. 
Zolkos, S. G., Goetz, S. J., \& Dubayah, R. (2013). A meta-analysis of terrestrial aboveground biomass estimation using LiDAR remote sensing. Remote Sensing of Environment, 128, 289-298. 